NBER WORKING PAPER SERIES

\title{
STICKY PRICES AND MONETARY POLICY: EVIDENCE FROM DISAGGREGATED U.S. DATA
}

Jean Boivin

Marc Giannoni

Ilian Mihov

Working Paper 12824

http://www.nber.org/papers/w12824

\author{
NATIONAL BUREAU OF ECONOMIC RESEARCH \\ 1050 Massachusetts Avenue \\ Cambridge, MA 02138 \\ January 2007
}

We thank Piotr Eliasz, Giorgio Primiceri, Robert Rich, and Mark Watson for valuable discussions, Jordi Gali, participants to the NBER Monetary Economics Summer Institute, the NY Area Monetary Policy Workshop, and the International Research Forum on Monetary Policy at the Federal Reserve Board for comments. We also thank Rashid Ansari, Guilherme Martins, Mehmet Pasaogullari and Mauro Roca for excellent research assistance. Boivin and Giannoni are grateful to the National Science Foundation for financial support (SES-0518770). The views expressed herein are those of the authors and do not necessarily reflect the views of the National Bureau of Economic Research.

(C) 2007 by Jean Boivin, Marc Giannoni, and Ilian Mihov. All rights reserved. Short sections of text, not to exceed two paragraphs, may be quoted without explicit permission provided that full credit, including $(\odot$ notice, is given to the source. 
Sticky Prices and Monetary Policy: Evidence from Disaggregated U.S. Data

Jean Boivin, Marc Giannoni, and Ilian Mihov

NBER Working Paper No. 12824

January 2007

JEL No. C3,D2,E31,E4,E5

\begin{abstract}
$\underline{\text { ABSTRACT }}$ components of prices and quantities move in opposite directions.

Jean Boivin

HEC Montréal

3000, chemin de la Côte-Sainte-Catherine

Montréal (Québec)

Canada H3T 2A7

and NBER

jean.boivin@hec.ca

Marc Giannoni

Columbia Business School

3022 Broadway, Uris Hall 824

New York, NY 10027

and NBER

mg2190@columbia.edu

Ilian Mihov

INSEAD

Boulevard de Constance

77300 Fontainebleau

France

ilian.mihov@insead.edu
\end{abstract}

This paper disentangles fluctuations in disaggregated prices due to macroeconomic and sectoral conditions using a factor-augmented vector autoregression estimated on a large data set. On the basis of this estimation, we establish eight facts: (1) Macroeconomic shocks explain only about $15 \%$ of sectoral inflation fluctuations; (2) The persistence of sectoral inflation is driven by macroeconomic factors; (3) While disaggregated prices respond quickly to sector-specific shocks, their responses to aggregate shocks are small on impact and larger thereafter; (4) Most prices respond with a significant delay to identified monetary policy shocks, and show little evidence of a "price puzzle," contrary to existing studies based on traditional VARs; (5) Categories in which consumer prices fall the most following a monetary policy shock tend to be those in which quantities consumed fall the least; (6) The observed dispersion in the reaction of producer prices is relatively well explained by the degree of market power; (7) Prices in sectors with volatile idiosyncratic shocks react rapidly to aggregate monetary policy shocks; (8) The sector-specific 


\section{Introduction}

In this paper, we document the effects of macroeconomic fluctuations on disaggregated prices. Whether prices are generally flexible or sticky has been for a long time the subject of considerable controversy in macroeconomics. A proper assessment of the speed of price adjustment is crucial to understand the sources of business cycle fluctuations, as well as the effects of monetary policy on the economy.

Numerous studies focusing on specific wholesale or retail items have found evidence of prices maintained fixed for several months, in the U.S. ${ }^{1}$ Surveys of firms also suggest that a large fraction of prices remain constant for many months (Blinder, Canetti, Lebow, and Rudd, 1998). In addition, studies involving vector autoregressions (VAR) usually provide evidence of stickiness of the aggregate price level. For instance, under a wide range of identifying assumptions, following an unexpected monetary policy tightening, aggregate price indices are commonly found to remain unchanged for about a year and a half, and start declining thereafter (see, e.g., Christiano, Eichenbaum and Evans, 1999). Largely motivated by this evidence, many macroeconomic models including models used for policy analysis rest on the assumption that prices are sticky. Such models, sometimes augmented with mechanisms to increase the persistence in inflation, have been argued to replicate many features of aggregate data (e.g., Rotemberg and Woodford, 1997; Christiano, Eichenbaum and Evans, 2005; Smets and Wouters 2004), and in particular the delayed and persistent effects of monetary policy shocks on prices.

However, recent evidence on disaggregated prices series has cast doubts on the validity of existing models with price rigidities. For instance, Bils and Klenow (2004) find that disaggregated consumer prices are much more volatile than conventionally assumed in studies based on aggregate data. In fact, looking at 350 categories of consumer goods and services that cover about $70 \%$ of U.S. consumer expenditure, Bils and Klenow (2004) estimate that the median time between price changes

\footnotetext{
${ }^{1}$ See for instance Carlton (1986), Cecchetti (1986), Kashyap (1995), Levy, Bergen, Dutta and Venable (1997), MacDonald and Aaronson (2001), and Kackmeister (2001).
} 
is 4.3 months. ${ }^{2}$ The duration between price changes varies however considerably across sectors. ${ }^{3}$ Bils and Klenow (2004) argue that sectoral inflation rates are much more volatile and short-lived than implied by simple sticky-price models. Klenow and Kryvtsov (2005) document that when prices change, they change by more than $13 \%$ on average, or by $8.5 \%$ when adjusting for temporary sales. Golosov and Lucas (2003), in turn, calibrate a menu-cost model with both aggregate and idiosyncratic shocks to match these facts, and find that monetary policy shocks have large and rapid effects on aggregate prices but only very little effect on economic activity.

The evidence about relatively flexible individual prices thus contrasts sharply with the evidence obtained from aggregate price indices. While simple sticky-price models designed to explain aggregate price behavior appear to explain poorly the behavior of more disaggregated price series, models with relatively flexible sectoral prices do not seem to explain the empirical evidence obtained from aggregate series.

How then, can the facts just laid out be reconciled? One possibility is that studies based on aggregate series mistakenly assume that prices are sticky in the face of macroeconomic fluctuations, when in fact prices adjust more frequently to changes in economic conditions. In such a case, sectoral prices would be expected to respond on average rapidly to macroeconomic disturbances such as monetary policy shocks. And they would be expected to respond more rapidly in sectors that adjust prices more frequently. Another possibility is that prices respond differently to sectoral and macroeconomic shocks. In that case, individual prices may respond rapidly and strongly to shocks specific to the particular price categories, but may adjust more slowly to aggregate macroeconomic factors.

In addition, while aggregate inflation is often argued to be persistent over long samples ${ }^{4}{ }^{\text {dis- }}$ aggregated series appear much more transient. Several authors have argued that the apparent persistence of aggregate inflation may reflect an aggregation bias or a structural break in the

\footnotetext{
${ }^{2}$ The median duration remains below 5 months when they account for temporary sales. More recently, however, Nakamura and Steinsson (2006), analyzing CPI microdata, argue that the median duration is between 8 and 11 months when they exclude sales and price changes due to product substitutions. The upper bound is similar to the median duration found in Euro area data (see, e.g., Dhyne et al., 2005, and several other studies which are part of the Eurosystem Inflation Persistence Network).

${ }^{3}$ It ranges from less than a month (for gasoline prices) to more than 80 months (coin-operated apparel laundry and dry-cleaning).

${ }^{4}$ See, e.g., Fuhrer and Moore (1995), Galí and Gertler (1999), Cogley and Sargent (2001, 2005), Sims (2001), Stock (2001), Pivetta and Reis (2003), Levin and Piger (2003), Clark (2003).
} 
mean inflation during the sample. ${ }^{5}$ Yet, as another possible explanation, the differences in inflation persistence at the aggregate and disaggregate level may also be due to different responses to macroeconomic and sector-specific shocks.

One limitation of the existing evidence such as that of Bils and Klenow (2004), Klenow and Kryvtsov (2005) is that while they provide a careful description of individual prices movements, they do not distinguish between sector-specific and aggregate sources of fluctuations. It thus not possible to infer from these studies whether sectoral prices respond rapidly or slowly, strongly or moderately to macroeconomic shocks. Such distinctions would however provide crucial insights on the determination of prices, hence guidance for the development of appropriate macroeconomic models.

In this paper, we disentangle the fluctuations in disaggregated U.S. consumer and producer prices which are due to aggregate macroeconomic factors from those due to sectoral conditions. We do so by estimating a factor-augmented vector autoregression (FAVAR) that relates a large panel of economic indicators and individual price series to a relatively small number of estimated common factors. This framework allows us to assess the relative importance of macroeconomic and sectoral disturbances in determining disaggregate price fluctuations, and to decompose the persistence in inflation in terms of macroeconomic and sector-specific factors. Using this, we can analyze the typical response of disaggregate prices to macroeconomic shocks and to sector-specific shocks.

In addition, we estimate the effects of U.S. monetary policy on disaggregated prices after identifying monetary policy shocks using the information from the entire data set. We study the magnitude of the price responses to monetary policy shocks, and whether monetary policy has delayed effects on prices. While extensive research has attempted to characterize the effects of monetary policy on macroeconomic indicators, little research has analyzed its effects on disaggregated prices. Two exceptions are Bils, Klenow and Kryvtsov (2003), and Balke and Wynne (2003). These authors estimate the responses of individual prices to a monetary policy shock by appending individual price series to a separately-estimated VAR. However, their estimated price responses

\footnotetext{
${ }^{5}$ Pesaran and Smith (1995) and Imbs, Mumtaz, Ravn and Rey (2005) argue that heterogeneity — across categories - in the persistence of individual series may result in a large estimated persistence of the aggregate even if individual series display on average little persistence. Cogley and Sargent (2001, 2005), Levin and Piger (2003) and Clark (2003) find that inflation persistence drops when they allow for changes in mean inflation over time.
} 
display a considerable "price puzzle", i.e., a price increase following an unexpected monetary policy tightening, which stands in sharp contrast to predictions of conventional models. As argued in Sims (1992) and Bernanke, Boivin and Eliasz (2005), such evidence of a price puzzle may be indicative of VAR misspecification due, e.g., to the lack of information considered in the VAR estimation. In the context of our data-rich FAVAR, this risk of misspecification is considerably reduced, as we use all of the available information in the estimation. Consistency of our estimates is furthermore guaranteed by the fact that we estimate within the same framework the parameters describing the dynamics of the common factors and the parameters that relate the individual price series to common factors.

After documenting the responses of prices to a monetary policy shock, we attempt to provide an explanation for the cross-sectional dispersion of price responses. To this end, we collect data on industry characteristics that are related to various theories of price stickiness. In general, models that allow for imperfect competition and variable speed of price adjustment predict that firms in very competitive industries will react quickly to changes in the economic environment (see Barro, 1972). The standard workhorse monetary model with Calvo pricing assumes a fixed degree of price stickiness as measured by the probability of re-optimizing prices, so that industry characteristics do not affect this probability. Extensions of this model allow differences in probabilities of re-optimizing prices across sectors (see, e.g., Aoki, 2001; Benigno, 2003; Woodford, 2003, Chap. 3; Carvalho, 2006), but these models still do not explain why differences in the speed of price adjustments might emerge as part of the optimizing behavior of firms. Nevertheless, in these New Keynesian models, one industry characteristic — the degree of competition — affects directly the degree of strategic complementarity (or "real rigidity" as in Ball and Romer, 1990) in price setting, and therefore the trajectory of price adjustment.

Our main findings can be summarized as follows:

First, most of the fluctuations in sectoral inflation rates are due to sector-specific factors. On average, only about $15 \%$ of inflation fluctuations are due to macroeconomic factors $(17 \%$ for personal consumption expenditure prices and $13 \%$ for producer prices). Thus, the relative flexibility of sectoral prices found by Bils and Klenow (2004) is to a large extent due to sector-specific disturbances. Consistent with the evidence on disaggregated price series, we also find considerable 
disparities in the magnitude of price changes and in the persistence of inflation across price categories, both for consumer and producer prices. These disparities are due to a large extent to differences in the volatility of sector-specific components, and only little to different responses to macroeconomic factors.

Second, sectoral inflation fluctuations are persistent, but this persistence is driven primarily by common macroeconomic components and not by sector-specific disturbances. While sector-specific shocks may cause large fluctuations in the individual inflation rates, these fluctuations are shortlived on average. In contrast, aggregate macroeconomic shocks tend to have more persistent effects on a wide range of sectoral inflation rates.

Third, prices and quantities respond differently to macroeconomic shocks and to sector-specific shocks. While sector-specific shocks induce an immediate and permanent change in sectoral prices and quantities, macroeconomic shocks have a small impact on prices and quantities but they generate larger effects thereafter.

Fourth, most prices respond with a significant delay to identified monetary policy shocks, and show little evidence of a "price puzzle," contrary to existing studies based on monetary policy shocks identified from small-scale VARs. This suggests that exploiting a large information set in the estimation provides more accurate estimates of the effects of monetary policy.

The picture that emerges then, is one in which many prices fluctuate considerably in response to sector-specific shocks, but they respond only sluggishly to aggregate macroeconomic shocks such as monetary policy shocks. This difference in responses to various shocks can explain why, at the disaggregated level, individual prices are found to be adjusted relatively frequently, while estimates of the degree of price rigidity are much higher when based on aggregate data. This explains why models that assume considerable price stickiness have often been successful at replicating the effects of monetary policy shocks.

Looking across price categories, we find that the observed dispersion in the reaction of producer prices is relatively well explained by the degree of market power, that prices in sectors with volatile idiosyncratic shocks react rapidly to aggregate monetary policy shocks, and that PCE categories in which prices fall the most following a monetary policy shock tend to be those in which quantities consumed fall the least. Finally, we find that the idiosyncratic components of prices and quantities 
move mostly in opposite directions suggesting that idiosyncratic shocks are supply-type shocks.

Our results are robust to changes in the sample. In particular we show that our main results are qualitatively similar for the period after 1984.

The rest of the paper is organized as follows. Section 2 reviews the econometric framework, by discussing the formulation and estimation of the FAVAR. In Section 3, we discuss various data sets used in our estimation. Section 4 presents empirical results about the sources of fluctuations in disaggregated prices. It includes a description of the price responses to sector-specific shocks and to macroeconomic fluctuations. Section 5 investigates the effects of monetary policy shocks and relates the responses of producer prices in various sectors to industry characteristics. Section 6 reports some robustness results for the post-1984 sample. Section 7 concludes.

\section{Econometric Framework: FAVAR}

The empirical framework that we consider is based on the factor-augmented vector autoregression model (FAVAR) described in Bernanke, Boivin and Eliasz (2005) (BBE). One of its key features is to provide estimates of macroeconomic factors that affect the data of interest, by systematically and consistently exploiting all information from a large set of economic indicators. In our application, we estimate the empirical model by exploiting information from a large number of macroeconomic indicators, as well as from disaggregated data. This framework is particularly well suited to decompose the fluctuations of each series into a common and a series-specific component. It also allows us to characterize the response of all data series to macroeconomic disturbances, such as monetary policy shocks. As BBE argue, this framework should lead to a better identification of the policy shock than standard VARs, because it explicitly recognizes the large information set that the Federal Reserve and financial market participants exploit in practice, and also because it does not require to take a stand on the appropriate measures of prices and real activity which can simply be treated as latent common components. A natural by-product of the estimation is to obtain impulse response functions for any variables included in the data set. In particular, this allows us to document the effect of monetary policy on disaggregated prices.

We only provide here a general description of our implementation of the empirical framework 
and refer the interested reader to BBE for additional details. We assume that the economy is affected by a vector $C_{t}$ of common components to all variables entering the data set. Since we will be interested in characterizing the effects of monetary policy, this vector of common components includes a measure of the stance of monetary policy. As in most related VAR applications, we assume that the Federal funds rate, $R_{t}$, is the policy instrument. It will be allowed to have pervasive effect throughout the economy and will thus be considered as a common component of all variables entering the data set. The rest of the common dynamics are captured by a $K \times 1$ vector of unobserved factors $F_{t}$, where $K$ is relatively small. These unobserved factors may reflect general economic conditions such as "economic activity," the "general level of prices," the level of "productivity," which are not easily captured by a few time series, but rather by a wide range of economic variables. We assume that the joint dynamics of $F_{t}$ and $R_{t}$ are given by

$$
C_{t}=\Phi(L) C_{t-1}+v_{t}
$$

where

$$
C_{t}=\left[\begin{array}{l}
F_{t} \\
R_{t}
\end{array}\right],
$$

and $\Phi(L)$ is a conformable lag polynomial of finite order $d$, which may contain a priori restrictions, as in standard structural VARs. The error term $v_{t}$ is i.i.d. with mean zero and covariance matrix $Q$.

The system (1) is a VAR in $C_{t}$. The additional difficulty, with respect to standard VARs, however, is that the factors $F_{t}$ are unobservable. We assume that the factors summarize the information contained in a large number of economic variables. We denote by $X_{t}$ this $N \times 1$ vector of "informational" variables, where $N$ is assumed to be "large," i.e., $N>K+1$. We assume furthermore that the large set of observable "informational" series $X_{t}$ is related to the common factors according to

$$
X_{t}=\Lambda C_{t}+e_{t}
$$

where $\Lambda$ is an $N \times(K+1)$ matrix of factor loadings, and the $N \times 1$ vector $e_{t}$ contains (mean-zero) sector-specific components that are uncorrelated with the common components $C_{t}$. These sector- 
specific components are allowed to be serially correlated and weakly correlated across indicators. Equation (2) reflects the fact that the elements of $C_{t}$, which in general are correlated, represent pervasive forces that drive the common dynamics of $X_{t}$. Conditional on the observed Federal funds rate $R_{t}$, the variables in $X_{t}$ are thus noisy measures of the underlying unobserved factors $F_{t}$. Note that it is in principle not restrictive to assume that $X_{t}$ depends only on the current values of the factors, as $F_{t}$ can always capture arbitrary lags of some fundamental factors. ${ }^{6}$

To estimate the system (1) - (2), we follow the two-step principal component approach described in BBE. In the first step, the space spanned by the common components, $C_{t}$, is estimated using the first $K+1$ principal components of $X_{t}$. While the estimation does not exploit the fact that $R_{t}$ is observed, Stock and Watson (2002) show that the principal components consistently recover the space spanned by both $F_{t}$ and $R_{t}$, when $N$ is large and the number of principal components used is at least as large as the true number of factors. In the second step, a structural VAR is estimated on these common components, after imposing that $R_{t}$ is one of the common components.

This procedure has the advantages of being computationally simple and easy to implement. As discussed by Stock and Watson (2002), it also imposes few distributional assumptions and allows for some degree of cross-correlation in the idiosyncratic error term $e_{t}$. Boivin and $\mathrm{Ng}(2005)$ document the good forecasting performance of this estimation approach compared to some alternatives. ${ }^{7}$

\section{Data}

The data set used in the estimation of our FAVAR is a balanced panel of 653 monthly series, for the period running from 1976:1 to 2005:6. All data have been transformed to induce stationarity. The details for this data set, as well as the transformation applied to each particular series, are in Appendices A - D. The data set includes 111 updated macroeconomic indicators used by BBE, and listed in Appendix A, which involve several measures of industrial production, various price indices, interest rates, employment as well as other key macroeconomic and financial variables.

\footnotetext{
${ }^{6}$ This is why Stock and Watson (1999) refer to (2) as a dynamic factor model.

${ }^{7}$ Note that this two-step approach implies the presence of "generated regressors" in the second step. According to the results of Bai (2003), the uncertainty in the factor estimates should be negligible when $N$ is large relative to $T$. Still, the confidence intervals on the impulse response functions reported below are based on a bootstrap procedure that accounts for the uncertainty in the factor estimation.
} 
These indicators have been found to collectively contain useful information about the state of the economy for the appropriate identification of monetary policy. We expanded the data set of BBE in two directions.

First, we appended disaggregated data published by the Bureau of Economic Analysis on personal consumption expenditure (PCE). Specifically, we collected 335 series on PCE prices and an equal number of series on real consumption. Among these series, 35 price series and 35 real consumption series were removed because of missing observations. In order to capture data for all expenditures reported, we removed the other series in the same categories and retained the series at the immediately higher level of aggregation. However, we removed from our data set aggregate price and real consumption series (except for overall aggregates), so as to count only once each category in the disaggregated data. We thus ended up with 190 disaggregated PCE price series and the 190 corresponding consumption series. At the level of disaggregation considered, we have for instance data on new domestic autos, bicycles, shoes, cereals, fresh fruit, taxicabs, and so on. In addition, we also included 4 price indices and 4 consumption aggregates (overall PCE, durable goods, nondurable goods, and services). Further details on these series are provided in Appendix B.

Second, in order to obtain a more detailed picture of the characteristics of price responses, we also collected over 600 series for producer prices at the 6-digit level of NAICS codes (corresponding to 4-digit SIC codes). Because of changes in definitions and data coverage, we managed to obtain only 154 series for a longer period starting in January 1976 and ending in June 2005. Appendix C provides a brief description of these series.

Besides the series just described, which we used to estimate the FAVAR, we also collected data on industry characteristics, which could help us validate or reject assumptions underlying models of price determination. The $\mathrm{C} 4$ ratio, provided by the Bureau of the Census, reports the percentage of total sales attributable to the four largest firms in the industry. As another measure of competition, we use also data on average gross profit rates from the Annual Survey of Manufacturing. This data is available on an annual basis from 1997 to 2001. The cross-sectional industry data is described in Appendix D. 


\section{Fluctuations in Disaggregated Prices: Macroeconomic Factors and Sector-Specific Shocks}

We estimated the system (1) - (2) for the period 1976:1- 2005:6, using the data just described, and assuming 5 latent factors in the vector $F_{t}$. We experimented with more factors, but none of our conclusions were affected. We used 13 lags in estimating (1). The estimated system allows us to analyze the sources of fluctuations in sectoral inflation rates. Note that for all of the price series considered, (2) implies that

$$
X_{i t}=\lambda_{i}^{\prime} C_{t}+e_{i t}
$$

where $X_{i t}$ contains the monthly log change in the respective price series. This formulation allows us to disentangle the fluctuations in sectoral inflation rates due to the macroeconomic factors represented here by the common components $C_{t}$ which have a diffuse effect on all data series from those due to sector specific conditions represented by the term $e_{i t}$. It also allows us to study to what extent the persistence in sectoral inflation rates is due to macroeconomic or sectoral shocks. Note that since $C_{t}$ is a vector which may contain elements with very different dynamics and the vectors of loadings $\lambda_{i}$ may differ across sectors, each sector-specific inflation rate may reveal different dynamics in response to macroeconomic disturbances. Recall also, that the sector-specific terms $e_{i t}$ are allowed to be serially correlated and weakly correlated across sectors.

\subsection{Sources of fluctuations and persistence}

In this subsection we discuss some summary statistics about the volatility and the persistence of both aggregate and disaggregated monthly inflation series. The next subsection proceeds with a discussion of the effects of sector-specific and macroeconomic shocks.

\subsubsection{Inflation volatility}

As is indicated in the first column of Table 1, the standard deviation of aggregate inflation amounts to $0.24 \%$ for the overall PCE series, and ranges between $0.24 \%$ and $0.42 \%$ for the inflation rates of durable goods, nondurable goods and services. Most of the volatility in aggregate inflation is due 
to fluctuations in common macroeconomic factors. In fact, the $R^{2}$ statistic, which measures the fraction of the variance in inflation explained by the common component $\lambda_{i}^{\prime} C_{t}$ lies above 0.5 for all of the aggregate measures.

The picture is however quite different for more disaggregated inflation series. As the lower panel of Table 1 shows, disaggregated inflation series are on average much more volatile than aggregate series. On average (across sectors), the standard deviation of monthly inflation is $1.15 \%$ for all price series considered $\left(0.97 \%\right.$ for PCE inflation and $1.36 \%$ for PPI inflation). ${ }^{8}$ As the columns two to four reveal, most of the inflation volatility is however due to sector-specific disturbances. In fact while the mean volatility of the common component to inflation lies at $0.33 \%$, the volatility of the sector specific component is more than three times as large. The results are roughly similar for PCE and PPI inflation rates. As a result, the $R^{2}$ statistic amounts to 0.15 on average (0.17 for PCE and 0.13 for PPI).

Table 1 also reveals a considerable amount of heterogeneity across sectors in the volatility of disaggregated inflation series. Whereas some series such as inflation of tenant-occupied rent fluctuate even less than the inflation rate of the aggregate index, other series like the consumption category "insurance premium for user-operated transportation" or the production category "other oilseed processing" have monthly standard deviations close to $10 \%$. This heterogeneity is due to a large extent to differences in the volatility of sector-specific conditions, and much less so to differences in the response to macroeconomic fluctuations. As the sector-specific components tend to cancel each other out, inflation in the aggregate price indices ends up being less volatile than most sector-specific inflation rates.

One interesting fact revealed by Figure 1 is that the volatility of the common and the sectorspecific components to inflation are strongly positively correlated across sectors. As shown in Tables 2a-2c the correlation between the volatility of idiosyncratic shocks $(S d(e i))$ and the volatility of the common component $(S d(c o m))$ is high both for PCE deflators $(0.69)$ and for PPI data (0.78). ${ }^{9}$

\footnotetext{
${ }^{8}$ The average volatility of disaggregated PCE inflation series, weighted with expenditure shares, is somewhat lower than the unweighted average, but the overall picture remains the same for the volatility as well as for other statistics described below.

${ }^{9}$ From a statistical point of view, there is no reason to expect that the portion of inflation volatility explained by the regression (common component) and the portion of inflation volatility explained by the error terms should be correlated across industries (or samples). Therefore, Figure 1 presents an interesting result that requires structural interpretation.
} 
Note that the inflation variance explained by the macroeconomic factors depends on the loadings represented by the matrix $\Lambda$. One interpretation is that these loadings reflect the price setting behavior of firms in various industries. Under this interpretation, Figure 1 reveals that firms in industries with volatile idiosyncratic shocks do also respond strongly to macroeconomic shocks. This is the case if frequent price adjustments necessitated by idiosyncratic volatility are also used as an opportunity to adjust to changes in the macroeconomic environment. That would be consistent, for instance, with a sticky price model a la Calvo with heterogeneity in the frequency of price adjustment across sectors as in Carvalho (2006). ${ }^{10}$

\subsubsection{Inflation persistence}

One characteristic of aggregate inflation often discussed is its persistence. To assess the degree of persistence, we fit for each inflation series $X_{i t}$ and each of its components, $\lambda_{i}^{\prime} C_{t}$ and $e_{i t}$ an $\operatorname{AR}(p)$ process, of the form

$$
w_{t}=\rho(L) w_{t-1}+\varepsilon_{t}
$$

where the lag-length $p$ is selected on the basis of BIC, and we measure the degree of persistence by the sum of the coefficients on all lags, $\rho(1)$. Not surprisingly, as we report in Table 1, fluctuations in aggregate inflation are persistent with a measure $\rho(1)$ of 0.9 for the PCE inflation rate, and ranging between 0.44 and 0.91 for the three main components of PCE inflation. This measured persistence likely suffers from an upward bias. In fact, as argued in Pesaran and Smith (1995) and Imbs, Mumtaz, Ravn, and Rey (2005), the estimated persistence is likely biased upward when the components of the aggregate index display heterogenous dynamics, and the persistence of the individual series and their variance are positively correlated. Another possible source of bias has to do with a possible change in mean inflation during the sample.

As Clark (2003) noted, the sectoral inflation series display much less persistence than the aggregated series over the long sample. Similarly, Altissimo, Mojon and Zaffaroni (2004) who estimated

\footnotetext{
${ }^{10}$ An alternative interpretation might be that industries with significant inherent volatility are riskier so that the degree of asymmetric information between firms and lenders is more acute (since it is more difficult for lenders to determine the state of the world). In this case, more idiosyncratic volatility should make firms more vulnerable to changes in monetary policy, which is known to affect the wedge between internal and external financing (e.g. Bernanke and Gertler, 1995).
} 
a factor model on disaggregated CPI inflation series in Europe also found that inflation rates of individual categories are on average more volatile and less persistent than the aggregate inflation rate, and display widespread heterogeneity across categories. In our data set, the persistence is 0.29 on average over all sectors ( 0.30 for PCE inflation and 0.28 for PPI inflation). The inflation persistence varies importantly across sectors. While it is negative for some producer and consumer prices, it gets above 0.9 for the "health insurance" category of "worker's compensation" and for "rental value of farm dwellings." Interestingly, while the inflation persistence is in some cases due to series-specific factors, such as in the categories just mentioned, the inflation persistence is for most series due to fluctuations in common macroeconomic factors. In fact, while the average persistence of the common components reaches 0.91 , the individual components display on average almost no persistence. There is however considerable heterogeneity in the persistence of the sector-specific component across sectors.

\subsubsection{Persistence and volatility}

Bils and Klenow (2004) emphasize that, for a particular process for marginal costs, the Calvo model predicts that a higher degree of price stickiness reduces the impact of exogenous shocks on current inflation, but that it increases the persistence inflation. Thus everything else equal, in sectors with

high price stickiness, the inflation rate should display a relatively low volatility and a relatively high persistence. Bils and Klenow (2004) argue that models such as the Calvo model are rejected by the data as they predict a strong negative correlation across sectors between the frequency of price adjustment and the persistence in sectoral inflation, while this correlation is positive in their data covering 123 consumer goods over the period 1995-2000, and only mildly negative in their longer data set.

While we do not have estimates of the frequency of price adjustment, as in Bils and Klenow (2004), we can nevertheless compare the correlations of inflation volatility and inflation persistence across sectors in our data set. We find a weakly negative correlation (-0.08) between volatility and persistence in the sector-specific component of inflation, as Table 2 indicates. Once we look at the common component of inflation, however, the persistence and the volatility of inflation are much more negatively correlated (-0.46). This explains in part why the Calvo model is more successful 
in describing the volatility and persistence of inflation fluctuations generated by macroeconomic disturbances, than those generated by sector-specific shocks.

\subsection{Effects of macroeconomic shocks and sector-specific shocks}

Prices may change for all sorts of reasons, including changes in costs, in productivity, or changes in demand for goods. While Bils and Klenow (2004) and Klenow and Kryvtsov (2005) provide very valuable evidence that most prices are changed relatively frequently, and on average by large amounts, their study does not identify the source of these changes. It is therefore not clear from these studies whether prices which tend to change frequently and by large amounts - e.g., due to large and frequent changes in sector specific conditions - also change readily to macroeconomic shocks. Clarifying this issue is particularly relevant to understand the effects of monetary policy. If fact, if prices were adjusting rapidly to monetary shocks, monetary policy would have little and only short-lived effects on economic activity, as in the model of Golosov and Lucas (2003). Our paper thus complements Bils and Klenow's (2004) study by documenting how prices respond to sector-specific shocks and macroeconomic disturbances.

The left panels of Figure 2 report the response of each of the sectoral (log) price level to an adverse shock to its own sector-specific component. It is the response to a drop in $e_{i t}$ by one standard deviation. These prices respond sharply and very promptly to sector-specific disturbances, and tend to reach their new equilibrium level shortly after the shock. Inflation rates show thus no persistence in response to the sector-specific shock. For PCE categories, we report in Figure 3 the responses of the corresponding quantities to an adverse sector-specific shock in consumption. Similarly to prices, quantities fall once-and-for-all to such a shock. They don't seem to revert to the initial value.

To understand better the shocks that underlie sector-specific disturbances, we report in Figure 4 the correlation between the sector-specific component of PCE prices and the corresponding sectorspecific component of PCE quantities. Figure 4 reports the histogram of the correlations over all sectors. As is clear from the figure, all correlations except for one are negative. ${ }^{11}$ This suggests that sector-specific shocks are overwhelmingly supply-type disturbances. This finding is consistent with

\footnotetext{
${ }^{11}$ The positive correlation refers to the category "insurance premiums for user-operated transportation."
} 
Franco and Philippon (2004) which by looking at a large panel of firms find that permanent shocks to productivity, largely uncorrelated across firms, explain a large fraction of the firms' dynamics.

While sector-specific shocks tend to shift prices and quantities permanently to a new level, the responses to macroeconomic disturbances are very different. The middle panels of Figure 2 show the responses of each sectoral price to an innovation (of minus one standard deviation) to its common component $\lambda_{i}^{\prime} C_{t}$. We do the same for the PCE quantities in Figure 3. Prices and quantities fall by a relatively moderate amount in the first couple of months after the shock, but then continue to fall over the subsequent months. This reveals important sluggishness in the responses of prices to macroeconomic disturbances, and persistence in inflation rates. This contrasts sharply with the responses to sector-specific shocks.

Of course, since we don't identify any structural macroeconomic shock in this exercise, we are describing the response to a combination of macroeconomic shocks. These figures do not allow us to exclude the possibility that there exist macroeconomic disturbances which cause a rapid and permanent change in prices. To address this shortcoming, we identify in the next section a particular macroeconomic shock, i.e., a monetary policy shock. To get a sense of the kind of macroeconomic shocks we are considering here, we note that they do have a permanent effect on both prices and quantities, and that for PCE categories the correlation between the common component of prices and of the corresponding quantities are widely distributed over the -1 to +1 interval (Figure 4 ). This suggests that the disturbances that are common to our large data set involve both supplyand demand-type shocks.

Overall the results of this section suggest that there is a much higher volatility of sectoral inflation rates than of aggregate inflation rates, and that changes in sector-specific conditions are the most important determinants of sectoral inflation rates. Fluctuations in the common components, however, are responsible for a significant fraction of the volatility of sectoral inflation rates, and generate most of the fluctuations in aggregate inflation. In addition, sectoral prices respond very differently to sector-specific shocks and to macroeconomic shocks. While sector-specific shocks may cause large fluctuations in sectoral inflation, these fluctuations are typically short lived so that prices tend to move immediately to their new permanent level. Aggregate macroeconomic shocks instead tend to have more persistent and sluggish effects on a wide range of sectoral inflation rates. 


\section{$5 \quad$ Effects of Monetary Policy Shocks}

We now turn to the discussion of the effects of monetary policy shocks on disaggregated prices. One advantage of studying their responses to monetary shocks is that this can be done with a minimum amount of identifying restrictions in the FAVAR. To investigate the effects of other macroeconomic shocks would require arguably more controversial identifying assumptions. Since Bernanke and Blinder (1992) and Sims (1992), it is common to use VARs to trace out the effects of monetary policy innovations on macroeconomic variables. VARs are particularly convenient for this as they merely require the identification of monetary policy shocks, leaving the rest of the macroeconomic model unrestricted. To maintain enough degrees of freedom, estimated VARs are typically lowdimensional, involving in general no more than six to eight variables. ${ }^{12}$ The small size of traditional VARs has however been criticized. In fact estimated monetary policy innovations are likely to be biased in small-sized VARs to the extent that central banks and the private sector make decisions on the basis of information not considered in these VARs. A common illustration of this problem is the "price-puzzle", i.e., the finding that the price level tends to increase slightly after a contractionary money policy shock, which contradicts most standard theories (see Sims, 1992). Another problem with small-sized VARs is that they don't allow us to understand the effects of monetary policy shocks on a large number of variables of interest.

Fortunately, as argued in BBE, the FAVAR described above allows us to address both of these shortcomings of traditional VAR. BBE provide a characterization of the effects of monetary policy on about twenty macroeconomic variables using estimated factors. In this paper, we focus on the effects of monetary policy on our large panel of prices.

\subsection{Identification of monetary policy shocks}

To identify the monetary policy shock, we follow the strategy described in BBE. The assumption is that none of the latent common components of the economy responds within a month to unanticipated changes in monetary policy. This is the FAVAR extension of the standard recursive identification of monetary policy shock in standard VARs. To implement it in a FAVAR, we

\footnotetext{
${ }^{12}$ Leeper, Sims and Zha (1996), using Bayesian priors consider slightly larger VARs containing up to about 20 variables.
} 
need to account for the added difficulty that the principal components are not associated with any particular economic concepts. However, when the number of data series $N$ is large, the principal components estimated from the entire data set, $\hat{C}\left(F_{t}, R_{t}\right)$, have the property that they should consistently recover $K+1$ independent, but arbitrary, linear combinations of the latent factors $F_{t}$ and the observed common factor, i.e., the Federal funds rate $R_{t}$. Since $R_{t}$ is not explicitly imposed as a common component in the first step, any of the linear combinations underlying $\hat{C}\left(F_{t}, R_{t}\right)$ could involve the Fed's policy instrument, $R_{t}$. It would thus not be valid to simply estimate a VAR in $\hat{C}\left(F_{t}, R_{t}\right)$ and $R_{t}$, and identify the policy shock recursively. Instead, the direct dependence of $\hat{C}\left(F_{t}, R_{t}\right)$ on $R_{t}$ must first be removed, which is achieved by exploiting a subset of the variables - prices and real-activity measures, but not financial variables - that are assumed not to respond within the month to changes in monetary policy. We refer readers to BBE for details on the implementation of the identification.

\subsection{Responses to monetary policy shocks}

We proceed with a description of the response of our data series to a monetary policy shocks, i.e., an unexpected increase (of one standard deviation) of the Federal funds rate. Figure 5a shows the response of the Federal funds rate, the index of industrial production - as an aggregate measure of economic activity - , and an aggregate price index (PCE deflator). The solid line shows the responses generated by our FAVAR and the dashed lines show the responses obtained from a standard VAR that include these three variables only. ${ }^{13}$ Figure $5 \mathrm{~b}$ shows similar impulse responses except that the VAR is estimated using the consumer price index (CPI) instead of the PCE deflator.

One important feature of this figure is that the responses of the price index and industrial production are very different for the FAVAR and the VAR. The VAR displays a price puzzle and a large effect of monetary policy on industrial production after four years, which is inconsistent with long-run money neutrality. The price puzzle is especially important for the VAR using the CPI data, in Figure 5b. Instead the FAVAR displays a more conventional response of industrial production, and essentially no response of the price index for the first few months following a monetary policy shock. As discussed in BBE, since the FAVAR nests the VAR specification, this

\footnotetext{
${ }^{13}$ The VAR includes 13 lags as is the case for the estimated equation (1) in the FAVAR.
} 
suggests that the FAVAR is able to exploit the relevant information from the data set, that Sims (1992) argued may be missing from small-sized VARs. Note that if the additional series added to the data set were irrelevant, they should not bias the estimated response, but they should rather result in less precise estimates. As a result, the fact that the responses of the price index and the industrial production are different for both specifications suggests that the FAVAR is exploiting relevant information, especially for the CPI data, in Figure 5b.

We now turn to the responses of more disaggregated price series to the monetary policy shock. The FAVAR is perfectly suited for such an exercise as it allows us to compute directly the responses of all of the variables in the data set. The right panels of Figure 2 contain the disaggregated PCE and PPI price responses to the same identified monetary policy shock. While we observe some heterogeneity in the responses, a striking feature is that most indices respond very little for several months following the shock, and start falling only later. In addition, only very few sectors display an important price puzzle. Recall that in order to identify the monetary policy shock, we assume that individual prices do not respond within the same month to changes in the Federal funds rate. However nothing in the estimated FAVAR constrains the response of price series in all months following the monetary policy shock.

The right panels of Figure 2 also plot the unweighted average response (thick solid line) and the response of the overall price index (thick dashed line). It is interesting to note that the average price responses to a monetary shock and the response of the aggregate price indices are very similar. This suggests that the weights used in aggregate price indices do not play an important role in characterizing the response in the overall price indices. The figure makes it clear that most of the disaggregated prices move little in the 6 months following the monetary shock, and start decreasing thereafter. As reported in Table 3, the cumulative decline in prices is only $0.09 \%$ over the first 6 months, but reaches $0.43 \%$ when cumulated over the first 12 months. The drop in prices is more pronounced for producer prices with a cumulated decline of $0.78 \%$ over the first year than for consumer prices (cumulated decline of $0.15 \%$ ). Among consumer prices, the prices of durable goods start falling more rapidly than nondurables and services, a fact noted by Erceg and Levin (2002) and Barsky, House and Kimball (2003), and attributed to the greater interest-rate sensitivity of durable goods. These price indices do not reveal a price puzzle. 
Overall, when they start falling following the monetary shock, prices tend to decline fairly steadily for a couple of years. This results in relatively persistent sectoral inflation movements. As reported in Table 3, the autocorrelation coefficients of inflation conditional on a monetary shock are all very high.

The right panel of Figure 3 represents the impulse responses of the PCE quantities to the same monetary policy shock. While on average the real consumption responses tend to fall subsequent to the monetary shock, before reverting back to the initial level, there is considerable variation across sectors. As for the price responses, the average real consumption responses displays some persistence. Interestingly, sectors in which prices fall the most following a monetary shock tend to be sectors in which quantities fall the least, as indicated in Figure 6. This figure displays the scatter plot across PCE categories of the cumulated responses of prices and quantities for six months following the monetary shock, and the regression line reveals a significant and negative slope. Similar pictures are obtained for longer horizons.

To the extent that one is interested in characterizing the behavior of the economy in response to monetary policy actions, our results provide empirical support for features such as price rigidities and inflation persistence often embedded in monetary models. Our findings, however, contrast sharply with those of Bils, Klenow, and Kryvtsov (2003) and Balke and Wynne (2003) which call for a rejection of conventional sticky-price models. These authors found the opposite conclusion mainly because they estimate an important price puzzle.

Bils, Klenow, and Kryvtsov (2003) estimate responses of 123 components of the CPI to a Federal funds innovation, where the latter innovations are extracted from a 7-variable monthly VAR. As the VAR is estimated independently from the disaggregated price data, the responses obtained constitute only rough estimates of the price responses. Based on frequencies of price adjustments reported in Bils and Klenow (2004), they consider two categories of price responses — the flexible price and sticky price categories - and they report the responses of the prices in both categories as well as their ratio. They argue that the movements in relative prices are inconsistent with a popular sticky-price model. Following an expansionary monetary policy shock, their estimated relative price (of flexible prices relative to sticky prices) declines initially and then increases, while in the model, the relative price increases temporarily before reverting back to zero. However, the 
main reason for their finding of an unconventional relative price response in the data is related to

the fact that their estimate of flexible-price responses display a price puzzle: the flexible prices fall initially in response a monetary policy expansion, and increase only later. In contrast, sticky prices do not show significant dynamics in the first 20 months.

Balke and Wynne (2003), instead, focus on components of the producer price index. After estimating a small-sized VAR and the response of components of the PPI to an identified monetary policy shock, they also find a substantial price puzzle in individual series, and thus conclude similarly to Bils, Klenow and Kryvtsov (2003) that the implied estimated evolution of relative prices in inconsistent with that predicted by sticky price models.

These studies make two key assumptions about the behavior of the macro-economy: i) that the macroeconomic dynamics can be properly uncovered from a small set of macroeconomic indicators, and ii) that macroeconomic dynamics can be modeled separately from the disaggregated prices. Based on the results of $\mathrm{BBE}$, and as argued above, the first assumption does not seem to be empirically valid and could be responsible for finding a price puzzle. The second assumption implies that disaggregated prices only have an effect on the macroeconomy through an observed aggregate index. The FAVAR framework that we consider in this paper relaxes these two assumptions as it allows us to incorporate more information in the estimation of the macroeconomic dynamics, and to model the disaggregated dynamics in a more flexible fashion. Interestingly, in contrast to these studies, we don't find any evidence of price puzzle in our estimated FAVAR. This implies that the ratio of flexible to sticky prices behaves as predicted by standard monetary models (including sticky price models) with flexible prices falling after a contractionary monetary policy shock.

\subsection{Cross-sectional variation in price responses}

Having estimated impulse responses of sectoral prices to monetary policy shocks, we now attempt to explain differences in prices responses with sectoral characteristics.

\subsubsection{Cumulated impulse responses and volatility of sectoral shocks}

One first set of interesting correlations pertains to the cumulative sum of the impulse responses to a monetary shocks over the first 6 months (sum6) and over the first 12 months (sum12). Two striking 
results are the strongly negative correlations of the cumulative sums (in the last two columns of Table 2) with the volatility $(S d(e i))$ and persistence of idiosyncratic shocks (rho(ei)). To interpret these correlations, we should point out that the sums of impulse responses are calculated for a contractionary monetary policy and therefore more negative numbers imply more price flexibility, i.e. faster price adjustment.

As illustrated further in Figure 7, in sectors with small enough sectoral shocks there is almost no price response to monetary shocks over the first 6 months. However the larger the sectorspecific volatility the higher the price responses to monetary policy shocks. This result confirms the interpretation of Figure 1, that industries with high inherent volatility adjust also faster to macroeconomic disturbances. Similar pictures are found for when we consider longer horizons. Such a finding appears consistent with the prediction of the state-dependent model of Gertler and Leahy (2006). In this model, firms are affected by idiosyncratic shocks and face a cost of adjusting prices. The model predicts that the more firms are affected by idiosyncratic shocks, the more they adjust prices conditional on a monetary policy shock. Alternatively, by referring to the costs of processing information, Reis (2006) presents a model of inattentive producers in which a higher volatility of shocks requires more frequent price updating.

In addition, we note that from Tables 2a-2c that the persistence of the idiosyncratic shocks is again negatively related to the responses of prices to monetary policy shocks. One possible interpretation is that in industries where we observe more persistence of the idiosyncratic component, firms adjust immediately to any shock because both common and idiosyncratic components are persistent. Those firms that experience rather transient idiosyncratic shocks wait to see if the current shock is persistent (macroeconomic) or not (idiosyncratic) and adjust only with a delay. Of course, these are raw correlations and it is not clear whether any of these relationships will remain significant after controlling for example for the degree of competition in the industry. Accordingly, we turn now to regression analysis.

\subsubsection{Responses of producer prices and industry characteristics}

For the producer price series we have collected data on industry characteristics by NAICS codes.

We can match now the responses of prices to these characteristics. Our goal is to provide evidence 
on the main explanatory factors for the dispersion in price responses observed in the right panels of Figure 2. To address this question we start with the following specification of the cross-industry price responses:

$$
\operatorname{IRFCU}_{i, h}=\alpha+\beta_{1} \operatorname{comp}_{i}+\beta_{2} S d(e)_{i}+\beta_{3} r h o(e)_{i}+\epsilon_{i}
$$

where $I R F C U_{i, h}$ is the cumulative deviation of the price level in industry $i$ after a monetary policy shock, $h$ periods after the shock. We present results for the deviation of prices 6 and 12 months after the shock. comp $i$ denotes the degree of competition. We also use two variables from the factor analysis: $S d(e)_{i}$ is a measure of the volatility of the idiosyncratic component and $r h o(e)_{i}$ is the persistence of this component. To check robustness we will also add other controls and deterministic components like dummy variables.

We start in Table 6 by using as a dependent variable the cumulative sum of price responses over the first six months. Column (1) reports that profit rates are strongly and positively correlated with price responses. Since our price variable is on average negative and higher flexibility implies more negative cumulative deviation, the result implies that more competitive industries (lower profit rates) have higher price flexibility. The mean profit rate is about $25 \%$ and a movement from the mean to a profit rate of $35 \%$ implies 0.15 percentage points smaller cumulated price change 6 months following a policy shock. This is consistent with standard sticky price models (see e.g., Woodford, 2003), as well as with theories based on rational inattention (Reis, 2006). In column (5), we include three dummy variables to control for potentially different average price dynamics. We use three broad categories - food and textiles (NAICS codes starting with 31; dummy is coded as $d 1$ ); paper, wood, chemicals (codes with 32; dummy is denoted by d2); and metallurgy, electronics and machinery (codes with 33; dummy is denoted by $d 3$ ). In all three cases the intercepts are negative signifying the absence on average of a price puzzle. Notably the extra flexibility of the model improves the fit, but does not alter the coefficient on profit rates. In column (6), by including an interaction term we test whether the relationship between market power and price flexibility differs across major industry categories, but we find little evidence of changes across major categories.

This positive relationship between price stickiness and competition within each sector contrasts with Bils and Klenow's finding (2004) that their preferred measure of market power — the C4 ratio 
- becomes insignificant once they control for prices of raw material goods. As in Bils and Klenow, we also find that the $\mathrm{C} 4$ ratio is not a robust predictor of price dynamics. We use the inverse of the ratio as a measure of elasticity of demand, and we report in column (2) that the inverse of the C4 ratio is not significantly related to price dynamics. However, our results based on mean profit rates imply that for producer prices, market power is robustly related to price dynamics in response to monetary shocks.

Columns (3) and (4) confirm the correlation from the correlation matrix - both idiosyncratic volatility and persistence are negatively related to price impulse responses. This implies that firms in industries with persistent and volatile idiosyncratic shocks adjust rapidly to changes in the macroeconomic environment. Interestingly, the result survives once we include as controls profit rates (column (7)) and the three dummy variables defined above (not shown in this table).

As a robustness check, we turn now to the results based on the cumulative response over the first 12 months. The results reported in Table 5 confirm the importance of market power as measured by profit rates and also confirm the importance of the volatility of the idiosyncratic shocks $(S d(e i))$ and its persistence measure $\left(r h o(e)_{i}\right)$. As before, the $\mathrm{C} 4$ is insignificant. Finally, in Table 6 we report regressions results for the price impulse responses from the 7 th to the 12 th month after the shock, and find again similar results. In column (8) we include also the sum of the impulse responses in the initial 6 months. The coefficient is highly significant and positive indicating that a larger portion of the price adjustment occurs in this second 6-month period.

To sum up, our sectoral analysis indicates that as predicted by models based on monopolistic competition, prices adjust more sluggishly in industries in which market power is higher. In addition we uncovered two other important determinants of price responses: idiosyncratic volatility and the persistence of industry-specific shocks.

\section{Robustness Results}

All of the results reported above are based on a sample that starts in 1976:1 and ends in 2005:6. Recent research has however provided evidence of widespread instability in many macroeconomic 
series $^{14}$, of changes in monetary policy behavior ${ }^{15}$ over our sample, and of an important reduction in output volatility since around 1984. To ensure that our results are not affected by such events, we reproduce our main results for the sample 1984:1 - 2005:6.

Table 7 reproduces Table 1 for the post-1984 sample. While the persistence in inflation is lower in that sample - with the decline in persistence due to a lower persistence in the common component - all of the qualitative results discussed in Section 4 remain valid. Most notably, it remains true that most of the volatility in sectoral inflation is explained by sector-specific disturbances. In fact, only about $10 \%$ of inflation fluctuations is attributable to macroeconomic factors. Even though the persistence in disaggregate inflation is lower in the post-1984 sample than in our full sample, that persistence remains due to macroeconomic factors.

Figure 8 reproduce the responses of disaggregated prices to sector-specific shocks, to macroeconomic shocks, and to monetary policy shocks. Once again, while there are some changes, the responses are qualitatively similar to the ones reported for the full sample in Figure 2. Importantly, the price responses to idiosyncratic shocks are very different from those to macroeconomic shocks, and disaggregated prices continue to respond with a significant delay to monetary policy shocks.

\section{Conclusion}

In this paper, we disentangle the fluctuations in disaggregated U.S. consumer and producer prices which are due to aggregate macroeconomic shocks from those due to shocks to individual price series. We do so by estimating a factor-augmented VAR that relates a large panel of economic indicators and of individual price series to a relatively small number of estimated common factors. After identifying monetary policy shocks using all of the information available, we estimate consistently the effects of U.S. monetary policy on disaggregated prices. This is important not only to get a better understanding of the nature of the fluctuations in disaggregated prices, and of how prices react to macroeconomic shocks, but also to assess the impact of monetary policy on prices in various sectors.

\footnotetext{
${ }^{14}$ Stock and Watson (1996), Boivin (1999), Stock and Watson (2002) have provided evidence of instability in VARs.

${ }^{15}$ Bernanke and Mihov (1998), Clarida, Galí and Gertler (2000), Cogley and Sargent (2001, 2005), Boivin (1999, 2006), Boivin and Giannoni (2002, 2006).
} 
We obtain several empirical results that can be summarized as follows:

1. At the level of disaggregation considered, most of the sectoral prices fluctuations appear to be due to sector-specific factors, and only about $15 \%$ of individual sectoral price fluctuations, on average, are due to aggregate macroeconomic factors.

2. Sectoral inflation fluctuations are relatively persistent, but this persistence is essentially due to the very high degree of persistence in the components driven by common or macroeconomic shocks, and not to sector-specific disturbances.

3. Sectoral prices respond very differently to sector-specific shocks and to macroeconomic shocks: while sector-specific shocks may cause large fluctuations in sectoral inflation, these fluctuations are typically short lived so that prices tend to move immediately to their new permanent level; aggregate macroeconomic shocks instead tend to have more persistent and sluggish effects on a wide range of sectoral inflation rates.

4. Most disaggregated prices respond with a significant delay to identified monetary policy shocks, and show little evidence of a "price puzzle," contrary to existing studies based on traditional VARs. The absence of a strong price puzzle suggests that by exploiting a large information set in the estimation of a FAVAR, we may obtain more accurate estimates of the effects of monetary policy.

5. PCE categories in which prices fall the most following a monetary policy shock tend to be those in which quantities consumed fall the least.

6. The observed dispersion in the reaction of producer prices to monetary policy shocks is relatively well explained by the degree of market power.

7. Prices react more rapidly to monetary policy shocks in sectors with volatile idiosyncratic and persistent idiosyncratic shocks.

8. The correlations between the idiosyncratic components of prices and quantities tend to be negative, suggesting that sector-specific shocks are mostly supply-type shocks. 
This collection of stylized facts on the response of disaggregated U.S. prices to various shocks presents challenges to current models of price determination. An evaluation of various models on the basis of these stylized facts is beyond the scope of this paper. Nevertheless, it is worth pointing out that our finding number 3 - namely that sectoral prices respond differently to macroeconomic and sector-specific shocks - may explain why sticky-price models such as the Calvo model have been so popular in characterizing the effects of monetary policy actions on aggregate variables, while they have been sharply criticized at the same time by authors focused on disaggregate price series.

Clearly, is would be desirable to have models that can fully account for the responses of aggregate and disaggregated prices to both macroeconomic and sector-specific disturbances. Some recent papers are very promising in this respect. Carvalho (2006) generalizes the Calvo model to allow for heterogeneity in price stickiness across sectors. He finds that in the presence of strategic complementarities, firms which adjust prices infrequently have a disproportionately large effect on the decisions of other firms, and thus on the aggregate price level. Even if most sectors have relatively flexible prices, and thus respond quickly to sector-specific disturbances, they may respond sluggishly to nominal shocks. Gertler and Leahy (2006) propose a state-dependent pricing model that involves volatile prices due to idiosyncratic shocks, but that predicts sluggish price responses to a monetary shock, as reported here, due to real rigidities. ${ }^{16}$ The model also predicts that a high volatility of idiosyncratic shocks should be associated with more volatile prices and a more volatile response to monetary shocks, as we find in the data. In yet another direction, recent models on rational inattention such as those proposed by Reis (2006) and Maćkowiak and Wiederholt (2006) are also able to generate different responses of sectoral prices to sector-specific shocks and aggregate shocks. The model of Reis (2006), for instance predicts that (i) stickiness is higher in industries with low price elasticity of demand; (ii) costs of processing information are positively related with inattentiveness; (iii) volatility of shocks requires more frequent updating.

Assessing the empirical success of each of these theories along the many dimensions documented

\footnotetext{
${ }^{16}$ In contrast, the state-dependent model of Golosov and Lucas (2003) which has idiosyncratic productivity shocks but which abstracts from strategic complementarities generates rapid and strong price responses following a monetary policy shock. Midrigan (2006), however, extends the model of Golosov and Lucas (2003) to a multi-product setting and calibrates the distribution of idiosyncratic shocks in a way that mitigates the price responses to monetary shocks.
} 
in this paper is not a trivial task. Even though a strict and literal interpretation of any of these models may always be rejected on some dimension, a fair assessment requires moving beyond the strict interpretation and determining whether some enriched version of existing theories can be successful. This is in our view an important avenue for future research. 


\section{References}

[1] Altissimo, Filippo, Benoît Mojon, and Paolo Zaffaroni (2004), "Fast Micro and Slow Macro: Can Aggregation Explain the Persistence of Inflation?" manuscript, European Central Bank.

[2] Aoki, Kosuke (2001), "Optimal Monetary Policy Responses to Relative Price Changes," Journal of Monetary Economics 48: 55-80.

[3] Bai, Jushan (2003), "Inferential Theory for Factor Models of Large Dimensions," Econometrica 71(1): 135-72.

[4] Balke, Nathan S., and Mark A. Wynne (2003), "The Relative Price Effects of Monetary Shocks," FRB Dallas, Working Paper no. 0306.

[5] Ball, Laurence, and David Romer (1990), "Real Rigidities and the Non-Neutrality of Money," Review of Economic Studies 57: 183-203.

[6] Barro, Robert J. (1972), "A Theory of Monopolistic Price Adjustment," Review of Economic Studies 39: 17-26.

[7] Barsky, Robert, Christopher L. House, and Miles Kimball (2003), "Do Flexible Goods Prices Undermine Sticky Price Models?" NBER Working Paper 9832.

[8] Benigno, Pierpaolo (2003), "Optimal Monetary Policy in a Currency Area," Journal of International Economics.

[9] Bernanke, Ben S., and Alan S. Blinder (1992), "The Federal Funds Rate and the Channels of Monetary Transmission," American Economic Review 82(4): 901-921.

[10] Bernanke, Ben S., Jean Boivin and Piotr Eliasz (2005), "Measuring Monetary Policy: A Factor Augmented Vector Autoregressive (FAVAR) Approach," Quarterly Journal of Economics 120(1): 387-422.

[11] Bernanke, Ben S. and Mark Gertler (1995), "Inside the Black Box: The Credit Channel of Monetary Policy Transmission," Journal of Economic Perspectives 9, 27-48. 
[12] Bernanke, Ben, and Ilian Mihov (1998). "Measuring Monetary Policy." Quarterly Journal of Economics 113, 869-902.

[13] Bils, Mark, and Peter J. Klenow (2004), "Some Evidence on the Importance of Sticky Prices," Journal of Political Economy 112(5): 947-985.

[14] Bils, Mark, Peter J. Klenow, and Oleksiy Kryvtsov (2003), "Sticky Prices and Monetary Policy Shocks," Federal Reserve Bank of Minneapolis Quarterly Review 27(1): 2-9.

[15] Blinder, Alan S., Elie R. D. Canetti, David E. Lebow, and Jeremy B. Rudd (1998), Asking About Prices: A New Approach to Understanding Price Stickiness, Russell Sage Foundation, New York.

[16] Boivin, Jean (1999). "The Fed's Conduct of Monetary Policy: Has It Changed and Does It Matter?" Ph.D. thesis, Princeton University.

[17] Boivin, Jean (2006). "Has U.S. Monetary Policy Changed? Evidence from Drifting Coefficients and Real-Time Data," Journal of Money, Credit, and Banking, Vol. 38, No. 5.

[18] Boivin, Jean and Marc Giannoni (2002) "Assessing Changes in the Monetary Transmission Mechanism: A VAR Approach", Federal Reserve Bank of New York Economic Policy Review 8(1): $97-111$.

[19] Boivin, Jean and Marc Giannoni (2006) "Has Monetary Policy Become More Effective?" The Review of Economics and Statistics 88(3): 445-462.

[20] Boivin, Jean, and Serena Ng (2005), "Understanding and Comparing Factor-Based Forecasts," International Journal of Central Banking 1(3): 117-151.

[21] Carlton, Dennis W. (1986), "The Rigidity of Prices," American Economic Review 76, 637-658.

[22] Carvalho, Carlos (2006), "Heterogeneity in Price Stickiness and the New Keynesian Phillips Curve," Manuscript, Princeton University.

[23] Cecchetti, Stephen G. (1986), "The Frequency of Price Adjustment: A Study of the Newsstand Prices of Magazines," Journal of Econometrics 31, 255-274. 
[24] Christiano, Lawrence J., Martin Eichenbaum, and Charles Evans (1999), "Monetary Policy Shocks: What Have We Learned and to What End?" in J. Taylor and M. Woodford, eds., Handbook of Macroeconomics, Vol. 1A, Chap. 2. Amsterdam: North-Holland.

[25] Christiano, Lawrence J., Martin Eichenbaum, and Charles Evans (2005), "Nominal Rigidities and the Dynamic Effect of a Shock to Monetary Policy," Journal of Political Economy 113(1): $1-45$.

[26] Clark, Todd E. (2003), "Disaggregate Evidence on the Persistence of Consumer Price Inflation," manuscript, Federal Reserve Bank of Kansas City.

[27] Cogley, Timothy, and Thomas J. Sargent (2001), "Evolving Post-World War II U.S. Inflation Dynamics," NBER Macroeconomics Annual 16: 331-373.

[28] Cogley, Timothy, and Thomas J. Sargent (2005), "Drifts and Volatilities: Monetary Policies and Outcomes in the Post WWII US," Review of Economic Dynamics 8: 262-302.

[29] Dhyne, E., L. Álvarez, H. Le Bihan, G. Veronese, D. Dias, J. Hoffman, N. Jonker, P. Lünnemann, F. Rumler and J. Vilmunen (2005), "Price Setting in the Euro Area: Some Stylised Facts from Individual Consumer Price Data," European Central Bank Working Paper no. 524.

[30] Erceg, Christopher, and Andrew T. Levin (2002), "Optimal Monetary Policy with Durable Consumption Goods," International Finance Discussion Paper \#748, Board of Governors of the Federal Reserve System.

[31] Franco, Francesco, and Thomas Philippon (2004), "Firms and Aggregate Dynamics," Manuscript, New York University.

[32] Fuhrer, Jeffrey C. and George R. Moore (1995), "Inflation Persistence," Quarterly Journal of Economics 110, 127-159.

[33] Galí, Jordi, and Mark Gertler (1999), "Inflation Dynamics: A Structural Econometric Analysis," Journal of Monetary Economics 44, 195-222.

[34] Gertler, Mark, and John Leahy (2006), "A Phillips Curve with an SS Foundation," NBER Working Paper 11971. 
[35] Golosov, Mikhail, and Robert E. Lucas (2003), "Menu Costs and Phillips Curves," NBER Working Paper 10187.

[36] Imbs, Jean, Haroon Mumtaz, Morten O. Ravn, and Helene Rey (2005), "PPP Strikes Back: Aggregation and the Real Exchange Rate," Quarterly Journal of Economics 120, 1-44.

[37] Kackmeister, Alan (2001), "Has Retail Price Behavior Changed Since 1889? Evidence from Microdata," manuscript, University of California, Berkeley.

[38] Kashyap, Anil K. (1995), "Sticky Prices: New Evidence from Retail Catalogs," Quarterly Journal of Economics 110, 245-274.

[39] Klenow, Peter J. and Oleksiy Kryvtsov (2005) "State-dependent or Time-dependent Pricing: Does It Matter for Recent US Inflation?" NBER WP 11043.

[40] Leeper, Eric, Christopher A. Sims, and Tao Zha (1996), "What Does Monetary Policy Do?" Brookings Papers on Economic Activity 2.

[41] Levin, Andrew T., and Jeremy Piger (2003), "Is Inflation Persistence Intrinsic in Industrial Economies?" Working Paper 2002-023B, Federal Reserve Bank of St. Louis.

[42] Levy, Daniel, Mark Bergen, Shantanu Dutta, and Robert Venable (1997), "The Magnitude of Menu Costs: Direct Evidence from Large U.S. Supermarket Chains," Quarterly Journal of Economics 112 (3), 791-823.

[43] MacDonald, James N. and Daniel Aaronson (2001), "How Do Retail Prices React to Minimum Wage Increases?" manuscript, U.S. Department of Agriculture.

[44] Maćkowiak, Bartosz, and Mirko Wiederholt (2006), "Optimal Sticky Prices under Rational Inattention," manuscript, Humboldt University, Berlin.

[45] Midrigan, Virgiliu (2006), "Menu Costs, Multi-Product Firms, and Aggregate Fluctuations," manuscript, Ohio State University.

[46] Nakamura, Emi, and Jón Steinsson (2006), "Five Facts About Prices: A Reevaluation of Menu Cost Models," manuscript, Harvard University. 
[47] Pesaran, M. Hashem, and Ron Smith (1995), "Estimating Long-Run Relationships From Dynamic Heterogenous Panels," Journal of Econometrics 68: 79-113.

[48] Pivetta, Frederic, and Ricardo Reis (2003), "The Persistence of Inflation in the United States," manuscript, Harvard University.

[49] Reis, Ricardo (2006), "Inattentive Producers," Review of Economic Studies 73(1): 1-29.

[50] Rotemberg, Julio J., and Michael Woodford (1997), "An Optimization-Based Econometric Framework for the Evaluation of Monetary Policy," NBER Macroeconomics Annual, 297-346.

[51] Sims, Christopher A. (1992), "Interpreting the Macroeconomic Time Series Facts: The Effects of Monetary Policy," European Economic Review, 36(5), 975-1000.

[52] Sims, Christopher A. (2001), "Comment on 'Evolving Post-World War II U.S. Inflation Dynamics," NBER Macroeconomics Annual 16, 373-79.

[53] Smets, Frank, and Raf Wouters (2004), "Shocks and Frictions in US Business Cycles: A Bayesian DSGE Approach," manuscript, April.

[54] Stock, James H. (2001), "Comment on 'Evolving Post-World War II U.S. Inflation Dynamics," NBER Macroeconomics Annual 16, 379-87.

[55] Stock, James H., and Mark W. Watson (1996). "Evidence on Structural Instability in Macroeconomic Time Series Relations." Journal of Business and Economic Statistics 14, 11-30.

[56] Stock, James H., and Mark W. Watson (1999), "Forecasting Inflation," Journal of Monetary Economics 44, 293-335.

[57] Stock, James H., and Mark W. Watson (2002), "Macroeconomic Forecasting Using Diffusion Indexes," Journal of Business Economics and Statistics 20(2), 147-162.

[58] Woodford, Michael (2003), Interest and Prices: Foundations of a Theory of Monetary Policy, Princeton, Princeton University Press. 
Table 1: Volatility and persistence of inflation series

\begin{tabular}{|c|c|c|c|c|c|c|c|c|}
\hline & & \multicolumn{3}{|c|}{ Standard deviation } & \multirow[b]{2}{*}{$\mathrm{R} 2$} & \multicolumn{3}{|c|}{ Persistence } \\
\hline & & Inflation & $\begin{array}{r}\text { Common } \\
\text { comp. }\end{array}$ & $\begin{array}{l}\text { Sector- } \\
\text { specific }\end{array}$ & & Inflation & $\begin{array}{r}\text { Common } \\
\text { comp. }\end{array}$ & $\begin{array}{l}\text { Sector- } \\
\text { specific }\end{array}$ \\
\hline \multicolumn{9}{|c|}{ Aggregated series } \\
\hline \multirow[t]{4}{*}{ PCE } & Total & 0.24 & 0.21 & 0.11 & 0.77 & 0.90 & 0.95 & 0.13 \\
\hline & Durables & 0.33 & 0.25 & 0.21 & 0.60 & 0.88 & 0.97 & 0.08 \\
\hline & Nondurables & 0.42 & 0.30 & 0.30 & 0.50 & 0.44 & 0.91 & 0.22 \\
\hline & Services & 0.24 & 0.19 & 0.14 & 0.63 & 0.91 & 0.98 & 0.01 \\
\hline \multicolumn{9}{|c|}{ Disaggregated series } \\
\hline \multirow[t]{5}{*}{ All } & Average & 1.15 & 0.33 & 1.08 & 0.15 & 0.29 & 0.91 & -0.03 \\
\hline & Median & 0.75 & 0.27 & 0.71 & 0.12 & 0.30 & 0.93 & -0.02 \\
\hline & Minimum & 0.23 & 0.08 & 0.13 & 0.01 & -2.32 & 0.39 & -1.83 \\
\hline & Maximum & 11.67 & 1.85 & 11.59 & 0.68 & 0.96 & 0.99 & 0.87 \\
\hline & Std & 1.14 & 0.22 & 1.13 & 0.12 & 0.39 & 0.06 & 0.33 \\
\hline \multirow[t]{6}{*}{ PCE } & Average & 0.97 & 0.29 & 0.92 & 0.17 & 0.30 & 0.92 & -0.05 \\
\hline & Average (weighted) & 0.88 & 0.31 & 0.80 & 0.27 & 0.47 & 0.93 & 0.04 \\
\hline & Median & 0.65 & 0.23 & 0.60 & 0.12 & 0.36 & 0.95 & -0.02 \\
\hline & Minimum & 0.23 & 0.08 & 0.13 & 0.01 & -2.32 & 0.39 & -1.83 \\
\hline & Maximum & 11.67 & 1.85 & 11.59 & 0.68 & 0.96 & 0.99 & 0.87 \\
\hline & Std & 1.10 & 0.23 & 1.09 & 0.15 & 0.44 & 0.07 & 0.37 \\
\hline \multirow[t]{5}{*}{ PPI } & Average & 1.36 & 0.38 & 1.29 & 0.13 & 0.28 & 0.90 & 0.01 \\
\hline & Median & 0.92 & 0.30 & 0.87 & 0.11 & 0.27 & 0.91 & -0.01 \\
\hline & Minimum & 0.35 & 0.08 & 0.29 & 0.01 & -0.76 & 0.61 & -0.93 \\
\hline & Maximum & 7.73 & 1.15 & 7.66 & 0.43 & 0.91 & 0.98 & 0.63 \\
\hline & Std & 1.15 & 0.21 & 1.15 & 0.08 & 0.31 & 0.06 & 0.27 \\
\hline
\end{tabular}

Note: Weighted average of statistics for disaggregated PCE series is obtained using expenditure shares in year 2005 as weights. 
Table 2a. Cross-sectional correlations of various statistics (all prices)

\begin{tabular}{|c|c|c|c|c|c|c|c|c|c|c|c|}
\hline & Sd(m_it) & Sd(com) & Sd(ei) & R2 & rho(m_it) & rho(com) & rho(ei) & AC1 & AC12 & sum 6 & sum12 \\
\hline Sd(Trit) & 1 & 0.76 & 1.00 & -0.42 & -0.38 & -0.57 & -0.07 & 0.30 & 0.16 & -0.52 & -0.49 \\
\hline $\mathrm{Sd}(\mathrm{com})$ & & 1 & 0.74 & -0.12 & -0.11 & -0.46 & 0.12 & 0.30 & 0.21 & -0.49 & -0.64 \\
\hline Sd(ei) & & & 1 & -0.44 & -0.40 & -0.57 & -0.08 & 0.30 & 0.15 & -0.51 & -0.48 \\
\hline R2 & & & & 1 & 0.65 & 0.38 & 0.27 & -0.24 & -0.10 & 0.19 & 0.13 \\
\hline rho(m_it) & & & & & 1 & 0.41 & 0.59 & -0.02 & 0.04 & 0.00 & -0.06 \\
\hline rho(com) & & & & & & 1 & -0.02 & -0.31 & -0.20 & 0.31 & 0.32 \\
\hline rho(ei) & & & & & & & 1 & 0.20 & 0.13 & -0.19 & -0.26 \\
\hline$A C 1$ & & & & & & & & 1 & 0.84 & -0.44 & -0.55 \\
\hline AC12 & & & & & & & & & 1 & -0.39 & -0.52 \\
\hline sum6 & & & & & & & & & & 1 & 0.90 \\
\hline sum12 & & & & & & & & & & & 1 \\
\hline
\end{tabular}

Table 2b. Cross-sectional correlations of various statistics (PCE prices)

\begin{tabular}{|c|c|c|c|c|c|c|c|c|c|c|c|}
\hline & $S d\left(\pi \_i t\right)$ & Sd(com) & Sd(ei) & R2 & rho(m_it) & rho(com) & rho(ei) & AC1 & AC12 & sum 6 & sum12 \\
\hline Sd(m_it) & 1 & 0.73 & 1.00 & -0.37 & -0.48 & -0.61 & -0.23 & 0.23 & 0.18 & -0.29 & -0.36 \\
\hline Sd(com) & & 1 & 0.69 & -0.08 & -0.23 & -0.47 & -0.03 & 0.18 & 0.16 & -0.26 & -0.60 \\
\hline Sd(ei) & & & 1 & -0.40 & -0.49 & -0.61 & -0.24 & 0.23 & 0.18 & -0.29 & -0.34 \\
\hline $\mathrm{R} 2$ & & & & 1 & 0.65 & 0.35 & 0.33 & -0.22 & -0.10 & 0.10 & 0.03 \\
\hline rho(m_it) & & & & & 1 & 0.55 & 0.63 & -0.10 & -0.06 & 0.03 & -0.02 \\
\hline rho(com) & & & & & & 1 & 0.15 & -0.26 & -0.19 & 0.27 & 0.22 \\
\hline rho(ei) & & & & & & & 1 & 0.06 & 0.00 & -0.10 & -0.13 \\
\hline $\mathrm{AC1}$ & & & & & & & & 1 & 0.85 & -0.23 & -0.34 \\
\hline$A C 12$ & & & & & & & & & 1 & -0.35 & -0.47 \\
\hline sum6 & & & & & & & & & & 1 & 0.76 \\
\hline sum12 & & & & & & & & & & & 1 \\
\hline
\end{tabular}

Table 2c. Cross-sectional correlations of various statistics (PPI)

\begin{tabular}{|c|c|c|c|c|c|c|c|c|c|c|c|}
\hline & Sd(m_it) & $\mathrm{Sd}(\mathrm{com})$ & Sd(ei) & $\mathbf{R} 2$ & rho(m_it) & rho(com) & rho(ei) & AC1 & AC12 & sum6 & sum12 \\
\hline Sd(m_it) & 1 & 0.80 & 1.00 & -0.50 & -0.24 & -0.48 & 0.13 & 0.32 & 0.00 & -0.66 & -0.57 \\
\hline Sd(com) & & 1 & 0.78 & -0.13 & 0.11 & -0.39 & 0.35 & 0.42 & 0.19 & -0.66 & -0.72 \\
\hline Sd(ei) & & & 1 & -0.53 & -0.26 & -0.48 & 0.12 & 0.32 & -0.01 & -0.65 & -0.56 \\
\hline $\mathrm{R} 2$ & & & & 1 & 0.68 & 0.39 & 0.19 & -0.12 & 0.08 & 0.26 & 0.17 \\
\hline rho(m_it) & & & & & 1 & 0.13 & 0.53 & 0.21 & 0.30 & -0.03 & -0.14 \\
\hline rho(com) & & & & & & 1 & -0.31 & -0.28 & -0.08 & 0.34 & 0.36 \\
\hline rho(ei) & & & & & & & 1 & 0.47 & 0.35 & -0.28 & -0.40 \\
\hline AC1 & & & & & & & & 1 & 0.78 & -0.63 & -0.75 \\
\hline $\mathrm{AC} 12$ & & & & & & & & & 1 & -0.41 & -0.56 \\
\hline sum6 & & & & & & & & & & 1 & 0.93 \\
\hline sum12 & & & & & & & & & & & 1 \\
\hline
\end{tabular}

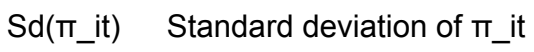

Sd(com) Standard deviation of common component of $\pi$ it

$\mathrm{Sd}(\mathrm{ei}) \quad$ Standard deviation of idio component of $\pi$ it

R2 R2 of the common component $\pi$ it

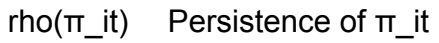

rho(com) Persistence of common component of $\pi$ it

rho(ei) Persistence of idio component of $\pi \_$it

AC1 First-order autocorrelation of $\pi$ it conditional on a monetary policy shock

AC12 Twelveth-order autocorrelation of $\pi$ it conditional on a monetary policy shock

sum6 Cummulative sum of IRF of $p \_$it over first 6 periods

sum12 Cummulative sum of IRF of $p$ it over first 12 periods 
Table 3: Response of price series to a monetary policy shock

\begin{tabular}{|c|c|c|c|c|c|c|c|}
\hline & & \multicolumn{4}{|c|}{ Autocorrelation of $\pi_{i t}$ conditional on shock } & \multicolumn{2}{|c|}{ Cumul. price responses } \\
\hline & & 1st-order & 3rd-order & 6th-order & 12th-order & 6 mths & 12 mths \\
\hline \multicolumn{8}{|c|}{ Aggregated series } \\
\hline \multirow[t]{4}{*}{ PCE } & Total & 0.97 & 0.91 & 0.82 & 0.63 & -0.02 & -0.21 \\
\hline & Durables & 0.97 & 0.90 & 0.80 & 0.61 & -0.06 & -0.21 \\
\hline & Nondurables & 0.98 & 0.93 & 0.84 & 0.67 & -0.05 & -0.54 \\
\hline & Services & 0.96 & 0.88 & 0.76 & 0.54 & 0.01 & -0.02 \\
\hline \multicolumn{8}{|c|}{ Disaggregated series } \\
\hline \multirow{5}{*}{ All } & Average & 0.97 & 0.90 & 0.80 & 0.58 & -0.09 & -0.43 \\
\hline & Median & 0.97 & 0.91 & 0.81 & 0.62 & 0.00 & -0.14 \\
\hline & Minimum & 0.93 & 0.79 & 0.54 & 0.18 & -1.96 & -6.23 \\
\hline & Maximum & 1.00 & 0.98 & 0.93 & 0.78 & 0.83 & 1.68 \\
\hline & Std & 0.01 & 0.04 & 0.07 & 0.13 & 0.35 & 1.00 \\
\hline \multirow[t]{6}{*}{ PCE } & Average & 0.97 & 0.89 & 0.78 & 0.55 & -0.01 & -0.15 \\
\hline & Average (weighted) & 0.97 & 0.89 & 0.78 & 0.55 & -0.02 & -0.20 \\
\hline & Median & 0.97 & 0.90 & 0.79 & 0.58 & 0.02 & -0.05 \\
\hline & Minimum & 0.93 & 0.79 & 0.54 & 0.19 & -0.91 & -4.15 \\
\hline & Maximum & 1.00 & 0.98 & 0.93 & 0.78 & 0.61 & 1.48 \\
\hline & Std & 0.01 & 0.04 & 0.08 & 0.14 & 0.20 & 0.64 \\
\hline \multirow[t]{5}{*}{ PPI } & Average & 0.97 & 0.92 & 0.82 & 0.63 & -0.19 & -0.78 \\
\hline & Median & 0.97 & 0.92 & 0.83 & 0.65 & -0.05 & -0.41 \\
\hline & Minimum & 0.94 & 0.82 & 0.62 & 0.18 & -1.96 & -6.23 \\
\hline & Maximum & 0.99 & 0.97 & 0.91 & 0.77 & 0.83 & 1.68 \\
\hline & Std & 0.01 & 0.03 & 0.06 & 0.11 & 0.46 & 1.23 \\
\hline
\end{tabular}

Note: Weighted average of statistics for disaggregated PCE series is obtained using expenditure shares in year 2005 as weights. 
Table 4: Cross-sectional dispersion in price responses for first 6 months after the shock

\begin{tabular}{|c|c|c|c|c|c|c|c|}
\hline & (1) & (2) & (3) & (4) & (5) & (6) & (7) \\
\hline Constant & $\begin{array}{c}-0.569 \\
(0.106)^{\star *}\end{array}$ & $\begin{array}{c}-0.156 \\
(0.072)^{*}\end{array}$ & $\begin{array}{c}0.142 \\
(0.039)^{\star \star}\end{array}$ & $\begin{array}{c}-0.195 \\
(0.036)^{\star \star}\end{array}$ & & & $\begin{array}{c}-0.151 \\
(0.132)\end{array}$ \\
\hline Gross Profit & $\begin{array}{c}1.540 \\
(0.355)^{\star \star}\end{array}$ & & & & $\begin{array}{c}1.598 \\
(0.368)^{\star \star}\end{array}$ & & $\begin{array}{c}1.013 \\
(0.449)^{*}\end{array}$ \\
\hline Invc4 & & $\begin{array}{l}-0.683 \\
(2.034)\end{array}$ & & & & & \\
\hline $\mathrm{Sd}(\mathrm{e})$ & & & $\begin{array}{l}-25.932 \\
(4.157)^{\star \star}\end{array}$ & & & & $\begin{array}{c}-22.549 \\
(3.769)^{\star \star}\end{array}$ \\
\hline rho(e) & & & & $\begin{array}{c}-0.524 \\
(0.129)^{\star \star}\end{array}$ & & & $\begin{array}{c}-0.243 \\
(0.116)^{\star}\end{array}$ \\
\hline $\mathrm{d} 1$ & & & & & $\begin{array}{c}-0.681 \\
(0.138)^{\star \star}\end{array}$ & $\begin{array}{c}-0.643 \\
(0.161)^{\star \star}\end{array}$ & \\
\hline $\mathrm{d} 2$ & & & & & $\begin{array}{c}-0.608 \\
(0.138)^{\star \star}\end{array}$ & $\begin{array}{c}-0.677 \\
(0.282)^{\star}\end{array}$ & \\
\hline d3 & & & & & $\begin{array}{c}-0.529 \\
(0.103)^{\star \star}\end{array}$ & $\begin{array}{c}-0.554 \\
(0.225)^{\star}\end{array}$ & \\
\hline d1*profit & & & & & & $\begin{array}{c}1.454 \\
(0.447)^{\star \star}\end{array}$ & \\
\hline d2*profit & & & & & & $\begin{array}{c}1.857 \\
(0.864)^{\star}\end{array}$ & \\
\hline d3*profit & & & & & & $\begin{array}{c}1.699 \\
(0.874)\end{array}$ & \\
\hline Observations & 149 & 149 & 151 & 151 & 149 & 149 & 149 \\
\hline R-squared & 0.13 & 0.00 & 0.42 & 0.09 & 0.27 & 0.27 & 0.50 \\
\hline
\end{tabular}

Robust standard errors in parentheses. $\left(^{\star}\right)$ denotes significant at $5 \% ;\left(^{\star \star}\right)$ denotes significant at $1 \%$ 
Table 5: Cross-sectional dispersion in price responses for first 12 months after the shock

\begin{tabular}{|c|c|c|c|c|c|c|c|}
\hline & (1) & (2) & (3) & (4) & (5) & (6) & (7) \\
\hline Constant & $\begin{array}{c}-1.890 \\
(0.264)^{\star \star}\end{array}$ & $\begin{array}{c}-0.629 \\
(0.181)^{\star \star}\end{array}$ & $\begin{array}{c}0.002 \\
(0.134)\end{array}$ & $\begin{array}{c}-0.774 \\
(0.093)^{\star \star}\end{array}$ & & & $\begin{array}{c}-0.878 \\
(0.319)^{\star \star}\end{array}$ \\
\hline Gross Profit & $\begin{array}{c}4.597 \\
(0.882)^{\star \star}\end{array}$ & & & & $\begin{array}{c}4.699 \\
(0.883)^{\star \star}\end{array}$ & & $\begin{array}{c}2.973 \\
(0.998)^{\star \star}\end{array}$ \\
\hline Invc4 & & $\begin{array}{l}-3.023 \\
(4.752)\end{array}$ & & & & & \\
\hline $\mathrm{Sd}(\mathrm{e})$ & & & $\begin{array}{c}-59.502 \\
(13.709)^{\star \star}\end{array}$ & & & & $\begin{array}{c}-47.903 \\
(12.032)^{\star \star}\end{array}$ \\
\hline rho(e) & & & & $\begin{array}{c}-1.844 \\
(0.323)^{\star \star}\end{array}$ & & & $\begin{array}{c}-1.105 \\
(0.270)^{\star \star}\end{array}$ \\
\hline $\mathrm{d} 1$ & & & & & $\begin{array}{c}-2.055 \\
(0.321)^{\star \star}\end{array}$ & $\begin{array}{c}-1.846 \\
(0.323)^{\star \star}\end{array}$ & \\
\hline $\mathrm{d} 2$ & & & & & $\begin{array}{c}-1.987 \\
(0.294)^{\star \star}\end{array}$ & $\begin{array}{c}-1.812 \\
(0.404)^{\star *}\end{array}$ & \\
\hline d3 & & & & & $\begin{array}{c}-1.822 \\
(0.278)^{\star \star}\end{array}$ & $\begin{array}{c}-2.357 \\
(0.692)^{\star \star}\end{array}$ & \\
\hline d1*profit & & & & & & $\begin{array}{c}3.909 \\
(0.818)^{\star \star}\end{array}$ & \\
\hline d2*profit & & & & & & $\begin{array}{c}4.045 \\
(1.163)^{\star \star}\end{array}$ & \\
\hline d3* profit & & & & & & $\begin{array}{c}6.876 \\
(2.644)^{\star}\end{array}$ & \\
\hline Observations & 149 & 149 & 151 & 151 & 149 & 149 & 149 \\
\hline R-squared & 0.16 & 0.00 & 0.31 & 0.15 & 0.41 & 0.42 & 0.46 \\
\hline
\end{tabular}

Robust standard errors in parentheses. $\left(^{*}\right)$ denotes significant at 5\%; $\left({ }^{* \star}\right)$ denotes significant at $1 \%$ 
Table 6: Cross-sectional dispersion in price responses for months 7 to 12 after the shock

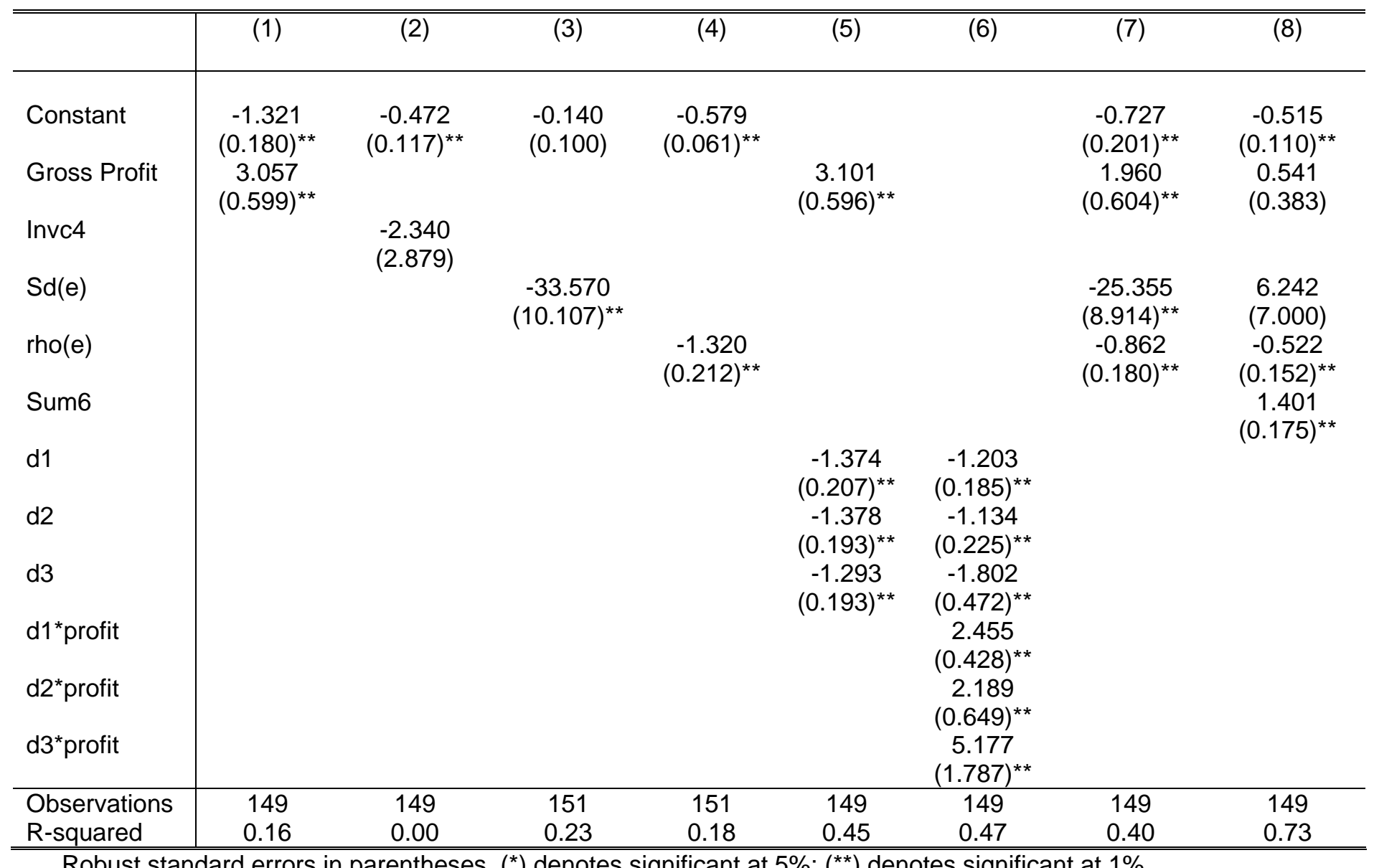

Robust standard errors in parentheses. $\left(^{\star}\right)$ denotes significant at 5\%; $\left(^{* \star}\right)$ denotes significant at $1 \%$ 
Table 7: Volatility and persistence of inflation series (Post-1984)

\begin{tabular}{|c|c|c|c|c|c|c|c|c|}
\hline & & \multicolumn{3}{|c|}{ Standard deviation } & \multirow[b]{2}{*}{$\mathrm{R} 2$} & \multicolumn{3}{|c|}{ Persistence } \\
\hline & & Inflation & $\begin{array}{r}\text { Common } \\
\text { comp. }\end{array}$ & $\begin{array}{l}\text { Sector- } \\
\text { specific }\end{array}$ & & Inflation & $\begin{array}{r}\text { Common } \\
\text { comp. }\end{array}$ & $\begin{array}{l}\text { Sector- } \\
\text { specific }\end{array}$ \\
\hline \multicolumn{9}{|c|}{ Aggregated series } \\
\hline \multirow[t]{4}{*}{ PCE } & Total & 0.16 & 0.14 & 0.08 & 0.73 & 0.33 & 0.71 & 0.01 \\
\hline & Durables & 0.26 & 0.16 & 0.20 & 0.39 & 0.78 & 0.95 & 0.12 \\
\hline & Nondurables & 0.40 & 0.33 & 0.21 & 0.71 & 0.14 & 0.59 & 0.30 \\
\hline & Services & 0.16 & 0.08 & 0.13 & 0.29 & 0.58 & 0.96 & -0.16 \\
\hline \multicolumn{9}{|c|}{$\underline{\text { Disaggregated series }}$} \\
\hline \multirow[t]{5}{*}{ All } & Average & 0.97 & 0.25 & 0.93 & 0.10 & 0.09 & 0.81 & -0.01 \\
\hline & Median & 0.64 & 0.16 & 0.62 & 0.07 & 0.06 & 0.85 & -0.02 \\
\hline & Minimum & 0.11 & 0.03 & 0.09 & 0.00 & -1.95 & -0.24 & -1.20 \\
\hline & Maximum & 7.31 & 2.79 & 7.17 & 0.76 & 1.03 & 0.97 & 0.81 \\
\hline & Std & 0.98 & 0.29 & 0.94 & 0.10 & 0.35 & 0.15 & 0.30 \\
\hline \multirow[t]{6}{*}{ PCE } & Average & 0.86 & 0.23 & 0.81 & 0.12 & 0.06 & 0.82 & -0.05 \\
\hline & Average (weighted) & 0.75 & 0.27 & 0.68 & 0.18 & 0.21 & 0.84 & 0.00 \\
\hline & Median & 0.57 & 0.15 & 0.55 & 0.07 & 0.02 & 0.88 & -0.05 \\
\hline & Minimum & 0.11 & 0.04 & 0.09 & 0.01 & -1.95 & -0.18 & -1.20 \\
\hline & Maximum & 7.31 & 2.79 & 7.17 & 0.76 & 0.92 & 0.97 & 0.81 \\
\hline & Std & 0.93 & 0.32 & 0.89 & 0.13 & 0.38 & 0.16 & 0.32 \\
\hline \multirow[t]{5}{*}{ PPI } & Average & 1.11 & 0.26 & 1.07 & 0.07 & 0.13 & 0.81 & 0.04 \\
\hline & Median & 0.75 & 0.17 & 0.72 & 0.06 & 0.09 & 0.84 & 0.03 \\
\hline & Minimum & 0.24 & 0.03 & 0.23 & 0.00 & -0.89 & -0.24 & -0.92 \\
\hline & Maximum & 6.33 & 1.45 & 6.27 & 0.33 & 1.03 & 0.96 & 0.70 \\
\hline & Std & 1.01 & 0.24 & 0.99 & 0.06 & 0.30 & 0.14 & 0.27 \\
\hline
\end{tabular}


Figure 1: Volatility of common and sector-specific components

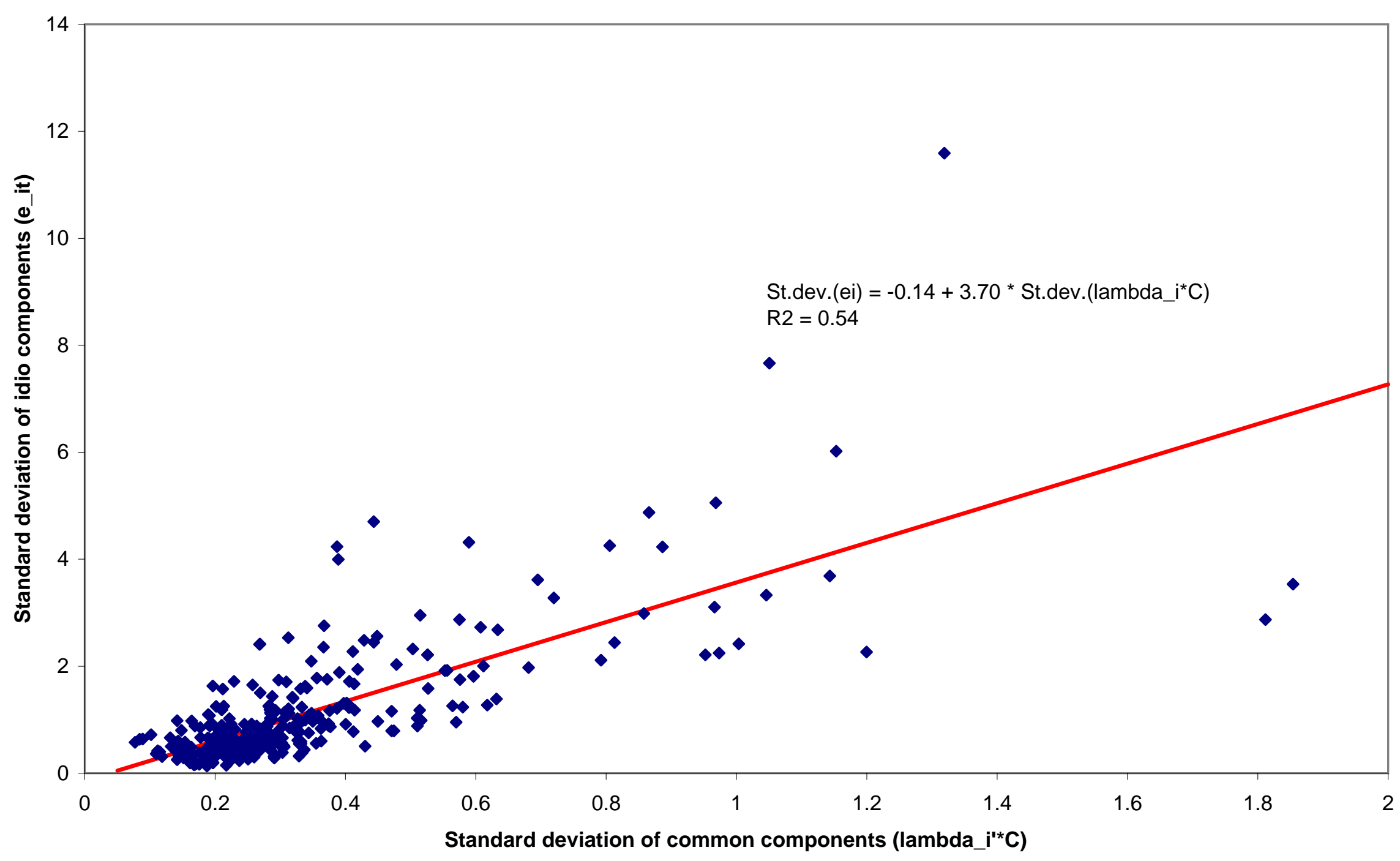



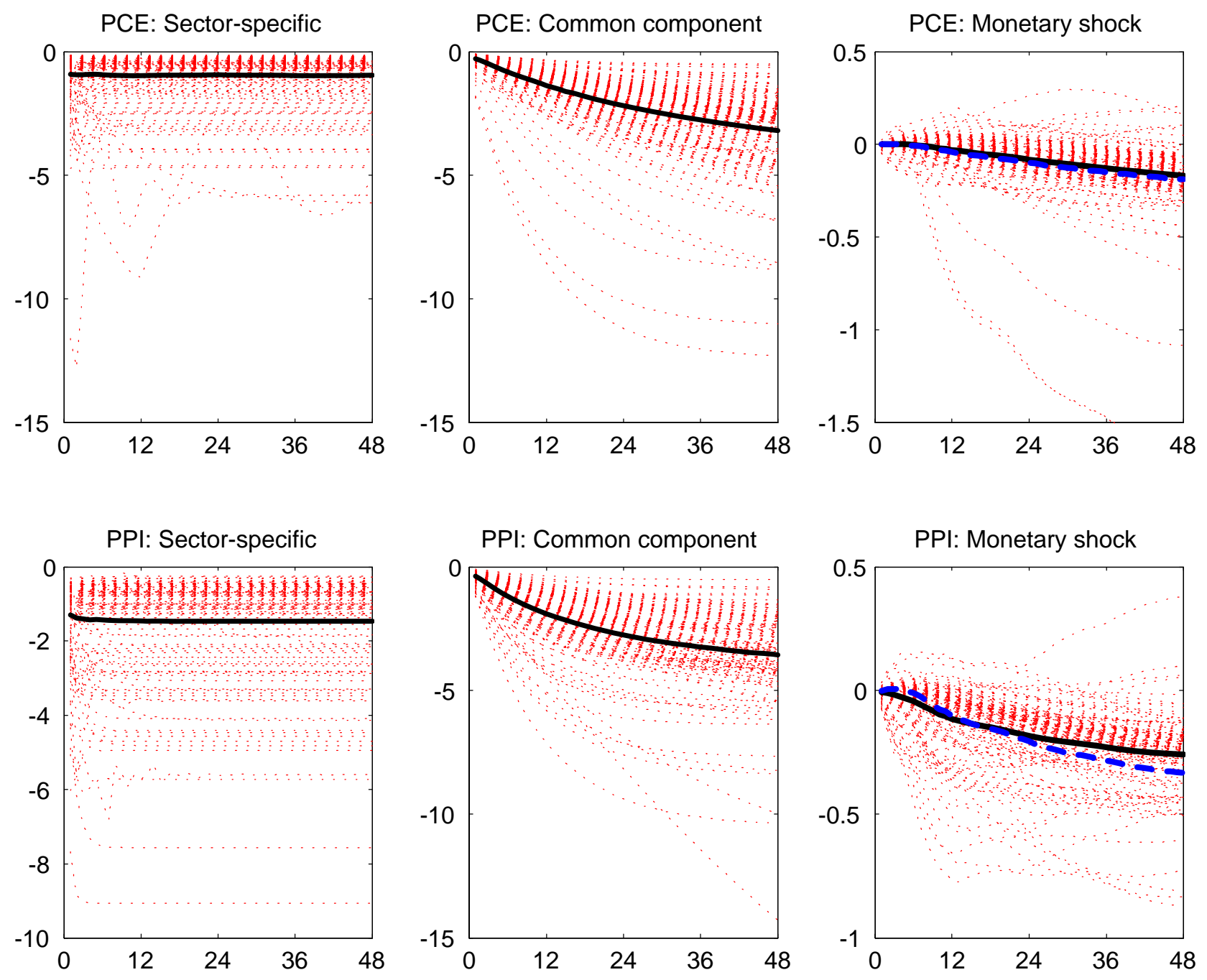

Figure 2. Sectoral price responses to various shocks

Notes: Estimated impulse responses of $(\log )$ sectoral prices to a sector-specific shock (left panels), to a shock to the common component (middle panels), and to an identified monetary policy shock (right panels). Fat lines represent unweighted average responses. Fat dashed lines represent the response of the aggregate PCE and PPI (finished) price indices to a monetary policy shock. 

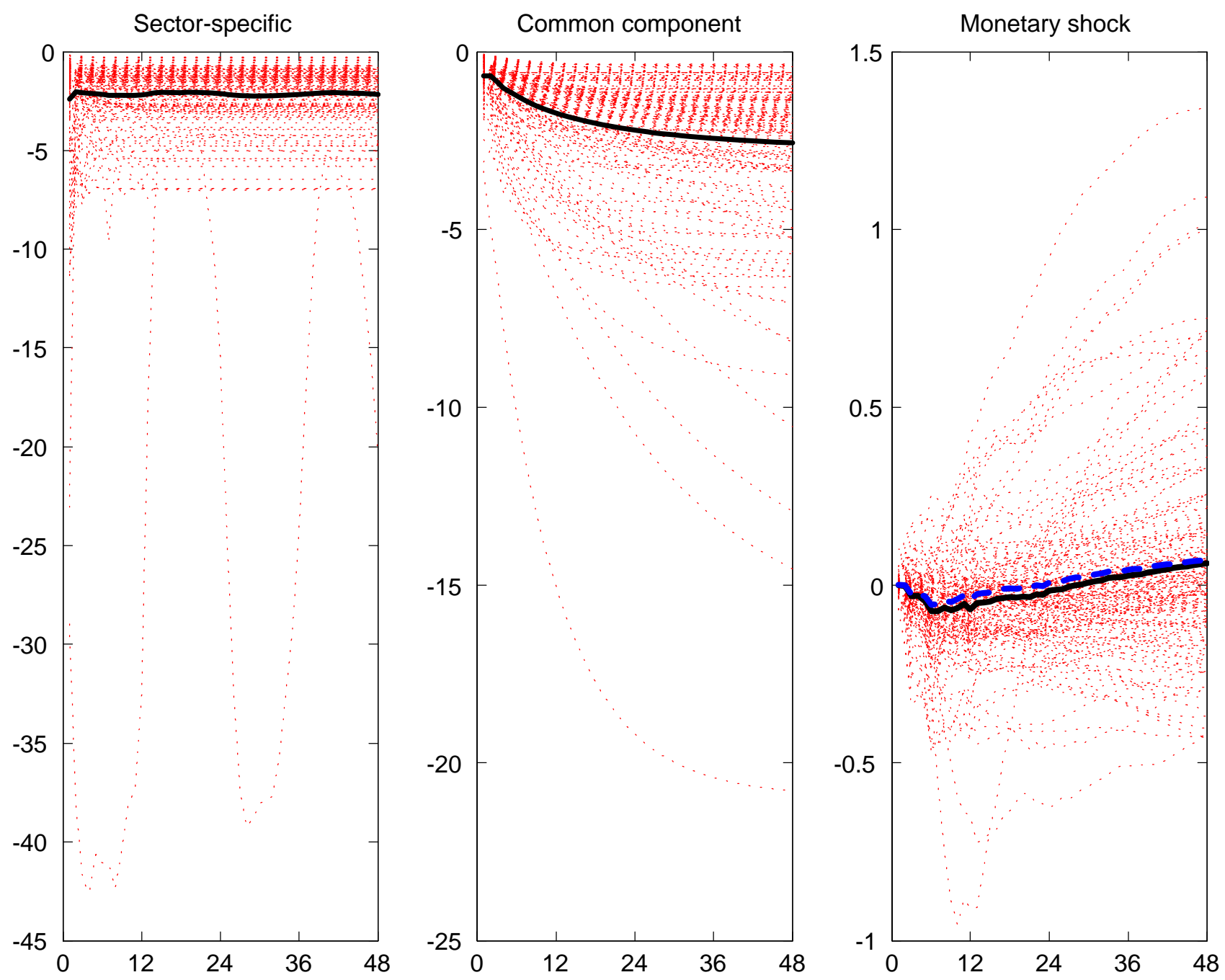

Figure 3: Responses of disaggregated consumption to various shocks

Notes: Estimated impulse responses of (log) sectoral PCE quantities to a sector-specific shock (left panel), to a shock to the common component (middle panel), and to an identified monetary policy shock (right panel). Fat lines represent unweighted average responses. The fat dashed line represents the response of the aggregate PCE quantity to a monetary policy shock. 

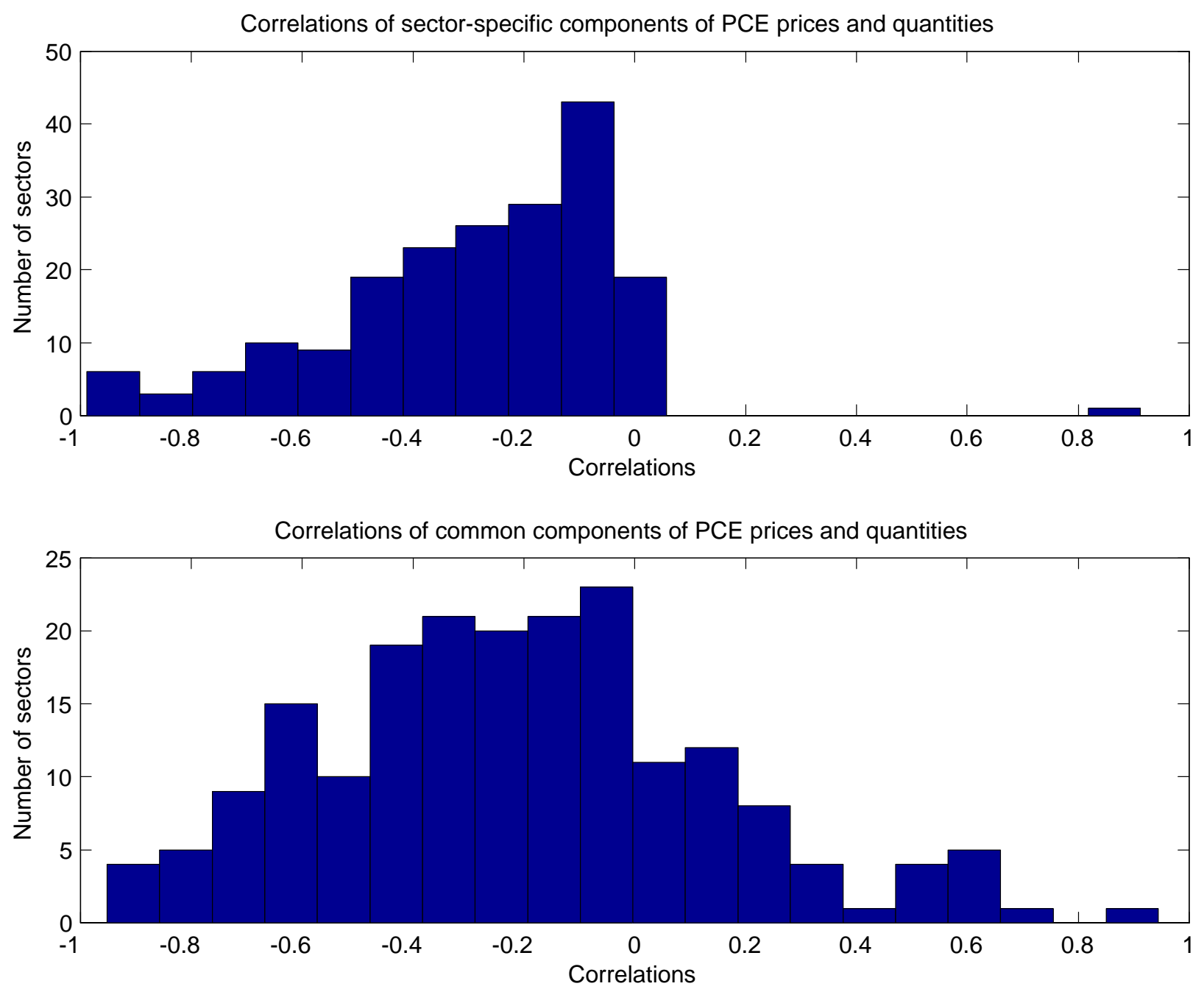

Figure 4: Correlations between components of PCE prices and quantities

Note: Each panel represents a histogram of correlations all PCE categories. The upper (lower) panel plots correlations between the sector-specific (common) component of PCE prices and quantities in any given sector. 

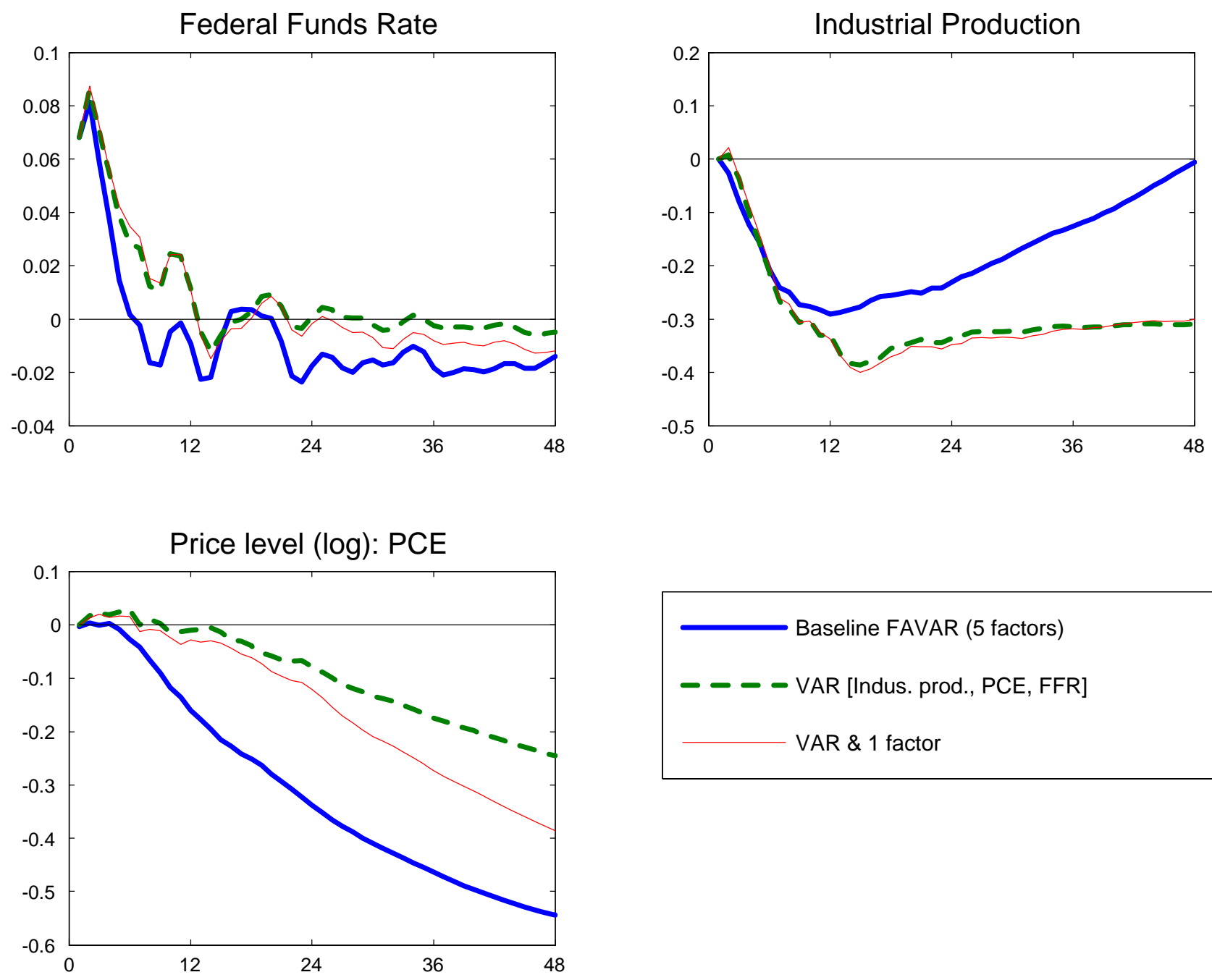

Figure 5a: Estimated impulse responses to an identified monetary policy shock (PCE) 

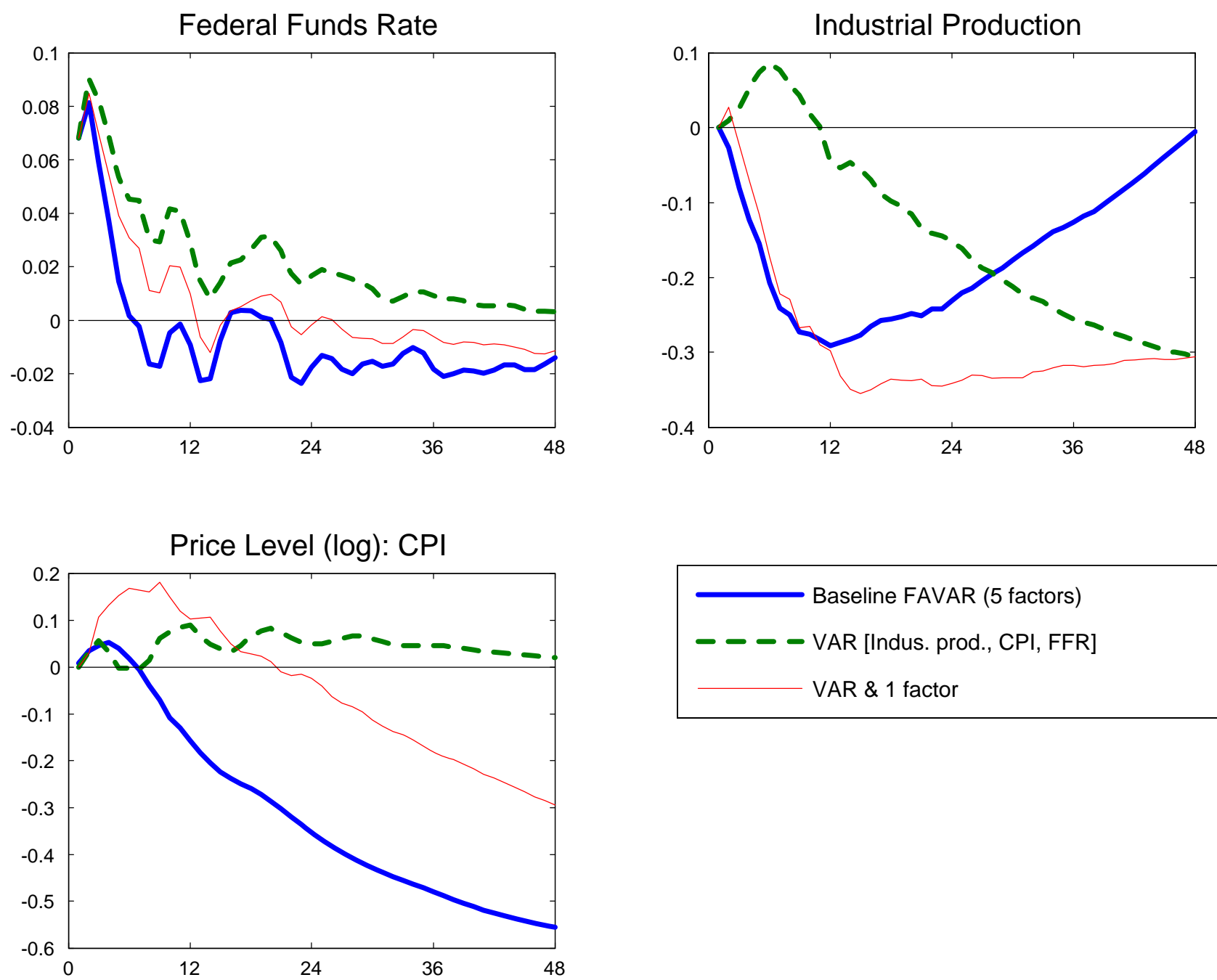

Figure 5b: Estimated impulse responses to an identified monetary policy shock (CPI) 
Figure 6: Impulse responses of PCE prices and quantities to monetary shock

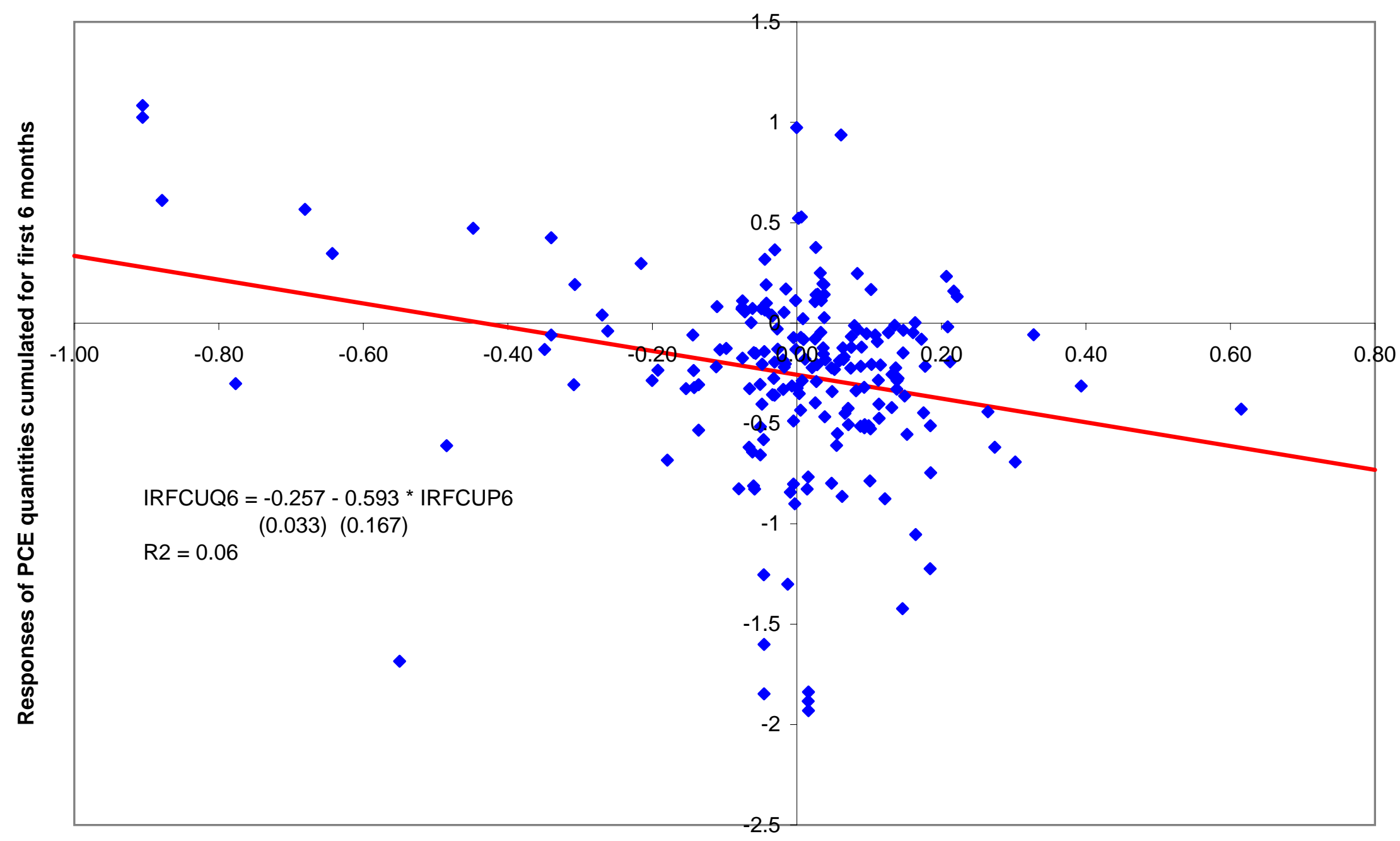

Responses of PCE prices cumulated for first 6 months 
Figure 7: Impulse responses to monetary shock and volatility of sector-specific components

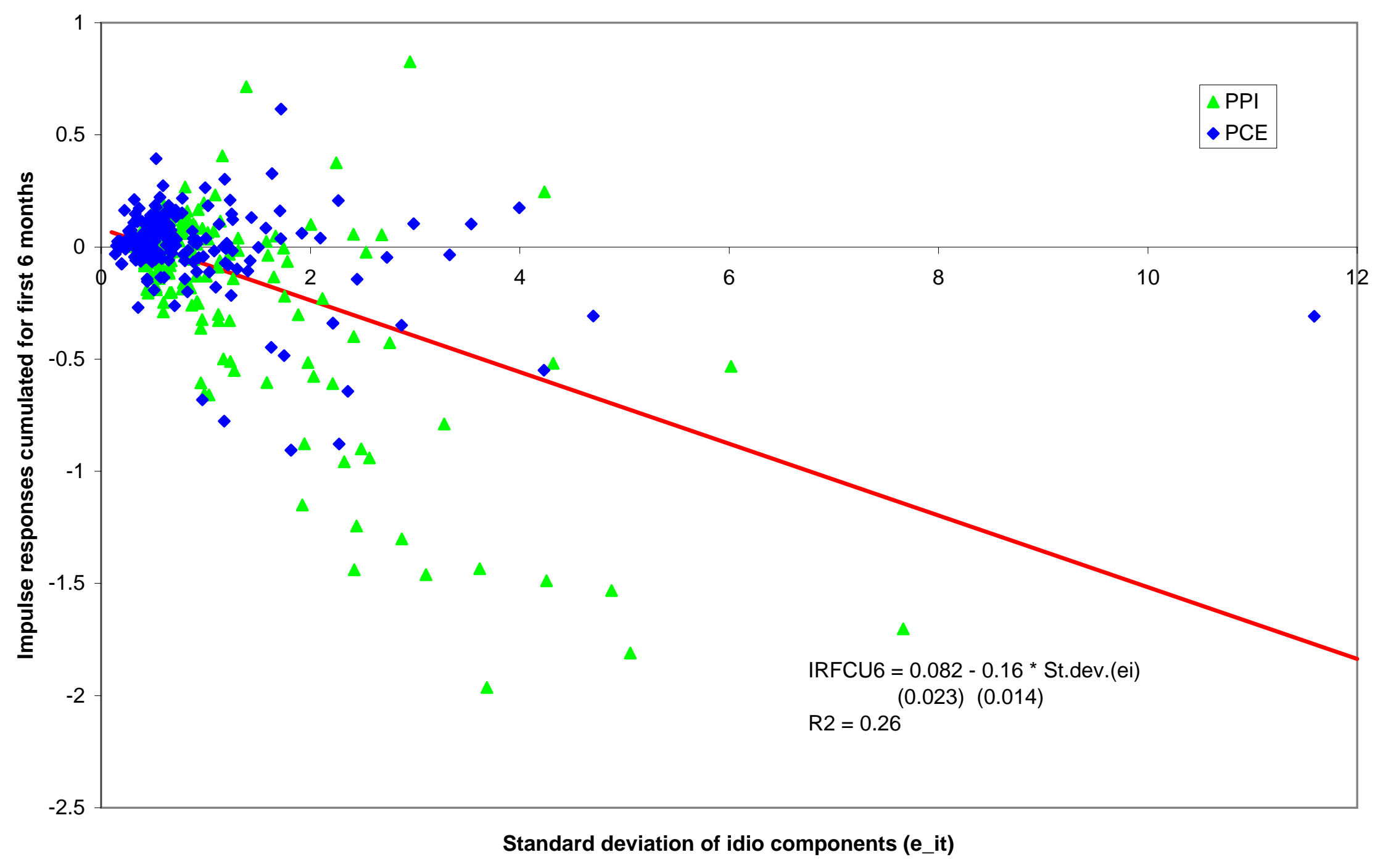



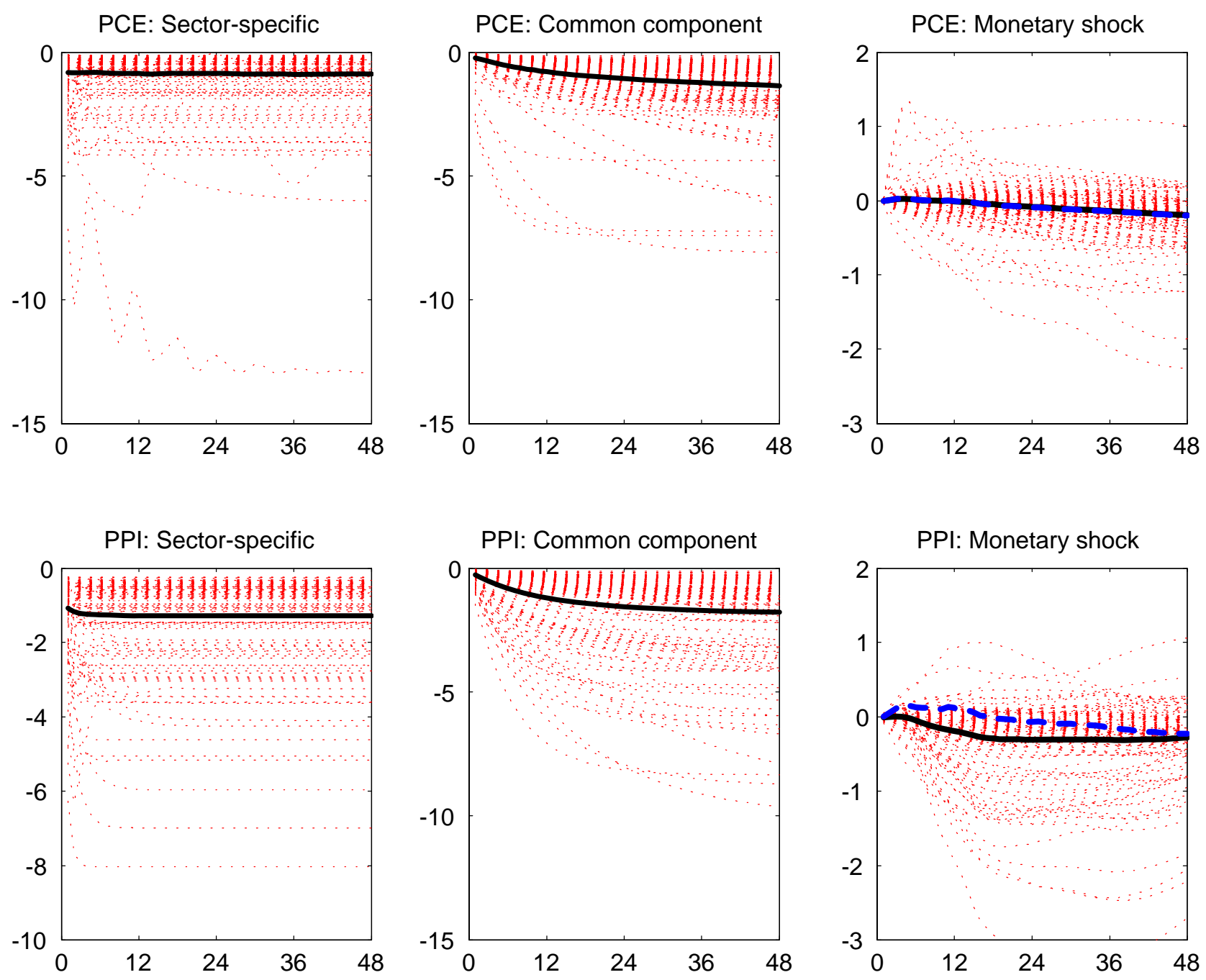

Figure 8. Sectoral price responses to various shocks in post-1984 sample

Notes: Estimated impulse responses of $(\log )$ sectoral prices to a sector-specific shock (left panels), to a shock to the common component (middle panels), and to an identified monetary policy shock (right panels). Fat lines represent unweighted average responses. Fat dashed lines represent the response of the aggregate PCE and PPI (finished) price indices to a monetary policy shock. 


\section{APPENDIX A - Main Data Set}

Format is as in Stock and Watson (2002) paper: series number; series mnemonic; data span; transformation code and series description as appears in the database. The transformation codes are: 1 - no transformation; 2 - first difference; 4 - logarithm; 5 - first difference of logarithm. Second differencing of logarithms was not used. Our main data set contains 230 monthly series with no missing observations. Series were directly taken from DRI/McGraw Hill Basic Economics Database.

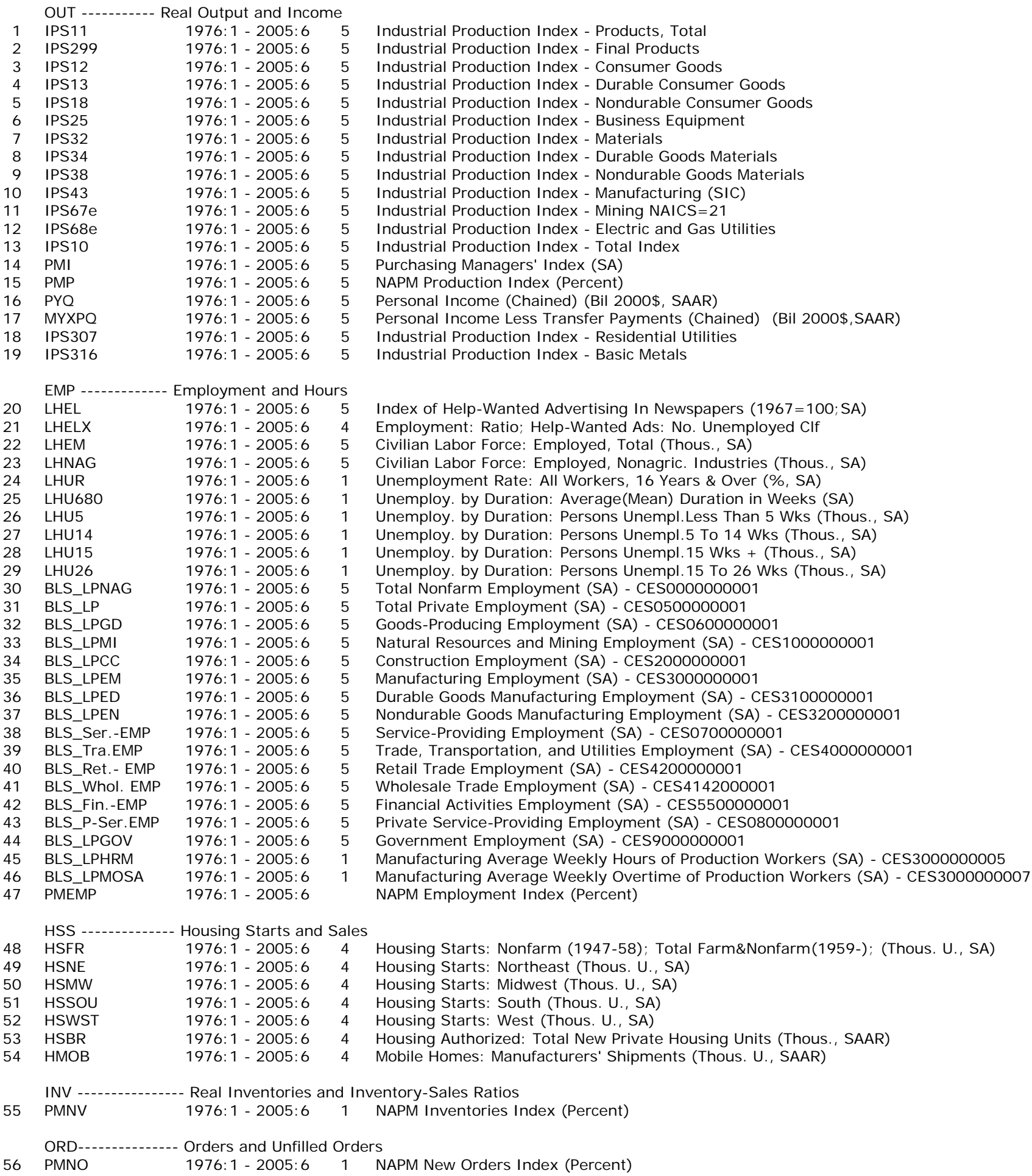




\begin{tabular}{|c|c|c|c|c|}
\hline 57 & PMDEL & 1976: 1 - 2005: 6 & 1 & NAPM Vendor Deliveries Index (Percent) \\
\hline 58 & MOCMQ & 1976: 1 - 2005: 6 & 5 & New Orders (Net) - Consumer Goods \& Materials, 1996 Dollars (BCI) \\
\hline 59 & MSONDQ & 1976: 1 - 2005: 6 & 5 & New Orders, Nondefense Capital Goods, In 1996 Dollars (BCI) \\
\hline $\begin{array}{l}60 \\
61 \\
62 \\
63 \\
64\end{array}$ & $\begin{array}{l}\text { SPR } \\
\text { FSPCOM } \\
\text { FSPIN } \\
\text { FSDXP } \\
\text { FSPXE } \\
\text { FSDJ }\end{array}$ & $\begin{array}{l}\text { Stock PriCES } \\
\text { 1976: } 1 \text { - 2005: } 6 \\
\text { 1976: } 1 \text { - 2005: } 6 \\
1976: 1-2005: 6 \\
1976: 1-2005: 6 \\
1976: 1-2005: 6\end{array}$ & $\begin{array}{l}5 \\
5 \\
1 \\
1\end{array}$ & $\begin{array}{l}\text { S\&P's Common Stock Price Index: Composite }(1941-43=10) \\
\text { S\&P's Common Stock Price Index: Industrials }(1941-43=10) \\
\text { S\&P's Composite Common Stock: Dividend Yield (\% Per Annum) } \\
\text { S\&P's Composite Common Stock: Price-Earnings Ratio (\%, NSA) } \\
\text { Common Stock Prices: Dow Jones Industrial Average }\end{array}$ \\
\hline $\begin{array}{l}65 \\
66 \\
67 \\
68\end{array}$ & $\begin{array}{l}\text { EXR } \\
\text { EXRSW } \\
\text { EXRJAN } \\
\text { EXRUK } \\
\text { EXRCAN }\end{array}$ & $\begin{array}{l}\text { - Exchange Rates } \\
\text { 1976: } 1 \text { - 2005: } 6 \\
\text { 1976: } 1 \text { - 2005: } 6 \\
\text { 1976: } 1 \text { - 2005: } 6 \\
1976: 1-2005: 6\end{array}$ & $\begin{array}{l}5 \\
5 \\
5 \\
5\end{array}$ & $\begin{array}{l}\text { Foreign Exchange Rate: Switzerland (Swiss Franc Per U.S.\$) } \\
\text { Foreign Exchange Rate: Japan (Yen Per U.S.\$) } \\
\text { Foreign Exchange Rate: United Kingdom (Cents Per Pound) } \\
\text { Foreign Exchange Rate: Canada (Canadian \$ Per U.S.\$) }\end{array}$ \\
\hline $\begin{array}{l}69 \\
70 \\
71 \\
72 \\
73 \\
74 \\
75 \\
76 \\
77 \\
78 \\
79 \\
80 \\
81 \\
82 \\
83\end{array}$ & $\begin{array}{l}\text { INT } \\
\text { FYFF } \\
\text { FYGM3 } \\
\text { FYGM6 } \\
\text { FYGT1 } \\
\text { FYGT5 } \\
\text { FYGT10 } \\
\text { FYAAAC } \\
\text { FYBAAC } \\
\text { SFYGM3 } \\
\text { SFYGM6 } \\
\text { SFYGT1 } \\
\text { SFYGT5 } \\
\text { SFYGT10 } \\
\text { SFYAAAC } \\
\text { SFYBAAC }\end{array}$ & 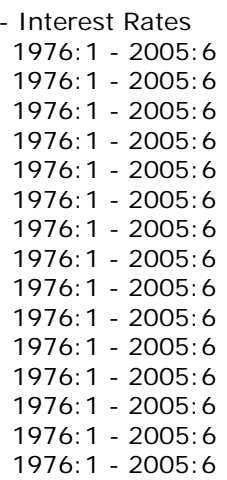 & $\begin{array}{l}1 \\
1 \\
1 \\
1 \\
1 \\
1 \\
1 \\
1 \\
1 \\
1 \\
1 \\
1 \\
1 \\
1 \\
1\end{array}$ & $\begin{array}{l}\text { Interest Rate: Federal Funds (Effective) (\% Per Annum, NSA) } \\
\text { Interest Rate: U.S.Treasury Bills, Sec Mkt,3-Mo.(\% Per Ann, NSA) } \\
\text { Interest Rate: U.S.Treasury Bills,Sec Mkt,6-Mo. (\% Per Ann, NSA) } \\
\text { Interest Rate: U.S.Treasury Const Maturities,1-Yr. (\% Per Ann, NSA) } \\
\text { Interest Rate: U.S.Treasury Const Maturities,5-Yr.(\% Per Ann, NSA) } \\
\text { Interest Rate: U.S.Treasury Const Maturities, 10-Yr.(\% Per Ann, NSA) } \\
\text { Bond Yield: Moody's AAA Corporate (\% Per Annum) } \\
\text { Bond Yield: Moody's BAA Corporate (\% Per Annum) } \\
\text { Spread FYGM3 - FYFF } \\
\text { Spread FYGM6 - FYFF } \\
\text { Spread FYGT1 - FYFF } \\
\text { Spread FYGT5 - FYFF } \\
\text { Spread FYGT10 - FYFF } \\
\text { Spread FYAAAC - FYFF } \\
\text { Spread FYBAAC - FYFF }\end{array}$ \\
\hline $\begin{array}{l}84 \\
85 \\
86 \\
87 \\
88 \\
89 \\
90 \\
91 \\
92 \\
93\end{array}$ & $\begin{array}{l}\text { MON } \\
\text { FM1 } \\
\text { FM2 } \\
\text { FM3 } \\
\text { FM2DQ } \\
\text { FMFBA } \\
\text { FMRRA } \\
\text { FMRNBA } \\
\text { FCLBMC } \\
\text { CCINRV } \\
\text { IMFCLNQ }\end{array}$ & 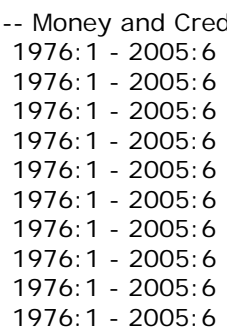 & $\begin{array}{l}\text { Qua } \\
5 \\
5 \\
5 \\
5 \\
5 \\
5 \\
5 \\
1 \\
5\end{array}$ & $\begin{array}{l}\text { tity Aggregates } \\
\text { Money Stock: M1(Curr,Trav.Cks, Dem Dep, Other Ck'able Dep) (Bil\$, SA) } \\
\text { Money Stock: M2(M1+O'nite Rps, Euro\$,G/P\&B/D Mmmfs\&SAv\&Sm Time Dep (Bil\$, SA) } \\
\text { Money Stock: M3(M2+Lg Time Dep,Term Rp's\&Inst nnly Mmmfs) (Bil\$, SA) } \\
\text { Money Supply - M2 In } 1996 \text { Dollars (BCI) } \\
\text { Monetary Base, Adj for Reserve Requirement Changes (Mil\$, SA) } \\
\text { Depository Inst Reserves: Total,Adj For Reserve Req Chgs (Mil\$, SA) } \\
\text { Depository Inst Reserves: Nonborrowed,Adj Res Req Chgs (Mil\$, SA) } \\
\text { Wkly Rp Lg Com'I Banks: Net Change Com'l \& Indus Loans (Bil\$, SAAR) } \\
\text { Consumer Credit Outstanding - Nonrevolving(G19) } \\
\text { Commercial \& Industrial Loans Oustanding In 1996 Dollars }\end{array}$ \\
\hline & PRI - - - - - & Price Indexes & & \\
\hline 94 & PMCP & $1976: 1-2005: 6$ & 1 & NAPM Commodity Prices Index (Percent) \\
\hline 95 & PWFSA & 1976: 1 - 2005: 6 & 5 & Producer Price Index: Finished Goods $(82=100,5 A)$ \\
\hline 96 & PWFCSA & 1976: 1 - 2005: 6 & 5 & Producer Price Index: Finished Consumer Goods $(82=100,5 A)$ \\
\hline 97 & PWIMSA & 1976: $1-2005: 6$ & 5 & Producer Price Index: Intermed Mat.Supplies \& Components $(82=100$, SA) \\
\hline 98 & PWCMSA & 1976: 1 - 2005: 6 & 5 & Producer Price Index: Crude Materials $(82=100, \mathrm{SA})$ \\
\hline 99 & PUNEW & 1976: 1 - 2005: 6 & 5 & CPI-U: All Items $(82-84=100, \mathrm{SA})$ \\
\hline 100 & PU83 & 1976: 1 - 2005: 6 & 5 & CPI-U: Apparel \& Upkeep (82-84=100,SA) \\
\hline 101 & PU84 & 1976: $1-2005: 6$ & 5 & CPI-U: Transportation $(82-84=100, \mathrm{SA})$ \\
\hline 102 & PU85 & 1976: 1 - 2005: 6 & 5 & CPI-U: Medical Care $(82-84=100, \mathrm{SA})$ \\
\hline 103 & PUC & $1976: 1-2005: 6$ & 5 & CPI-U: Commodities $(82-84=100, \mathrm{SA})$ \\
\hline 104 & PUCD & 1976: 1 - 2005: 6 & 5 & CPI-U: Durables $(82-84=100, \mathrm{SA})$ \\
\hline 105 & PUXF & $1976: 1-2005: 6$ & 5 & CPI-U: All Items Less Food $(82-84=100, S A)$ \\
\hline 106 & PUXHS & 1976: 1 - 2005: 6 & 5 & CPI-U: All Items Less Shelter $(82-84=100, \mathrm{SA})$ \\
\hline 107 & PUXM & 1976: 1 - 2005: 6 & 5 & CPI-U: All Items Less Medical Care $(82-84=100, \mathrm{SA})$ \\
\hline 108 & PSCCOM & 1976: 1 - 2005: 6 & 5 & Spot Market Price Index: BLS \& CRB: All Commodities $(1967=100)$ \\
\hline & AHE - - - - - & Average Houry Ear & & \\
\hline 109 & BLS_LEHCC & 1976: 1 - 2005: 6 & 5 & Construction Average Hourly Earnings of Production Workers (SA) - CES2000000006 \\
\hline 110 & BLS_LEHM & 1976: $1-2005: 6$ & 5 & Manufacturing Average Hourly Earnings of Production Workers (SA) - CES3000000006 \\
\hline 111 & $\begin{array}{l}\text { OTH }-\cdots \\
\text { HHSNTN }\end{array}$ & $\begin{array}{l}\text { Miscellaneous } \\
\text { 1976: } 1 \text { - 2005: } 6\end{array}$ & 1 & U. of Michigan Index of Consumer Expectations (Bcd-83) \\
\hline
\end{tabular}




\section{APPENDIX B - Personal Consumption Expenditures (price indexes and nominal expenditure)}

Format is as above: series number; series; data span; transformation code and series description as appears in the database. The transformation for all data was first difference of logarithms, which is coded as 5. This data set contains 194 monthly price series on Personal Consumption Expenditures with no missing observations, and 194 monthly real consumption series on Personal Consumption Expenditures. We describe here the 194 price series. The 194 corresponding real consumption series were ordered and transformed in a similar fashion. Series were downloaded from the underlying tables of the Bureau of Economic Analysis.

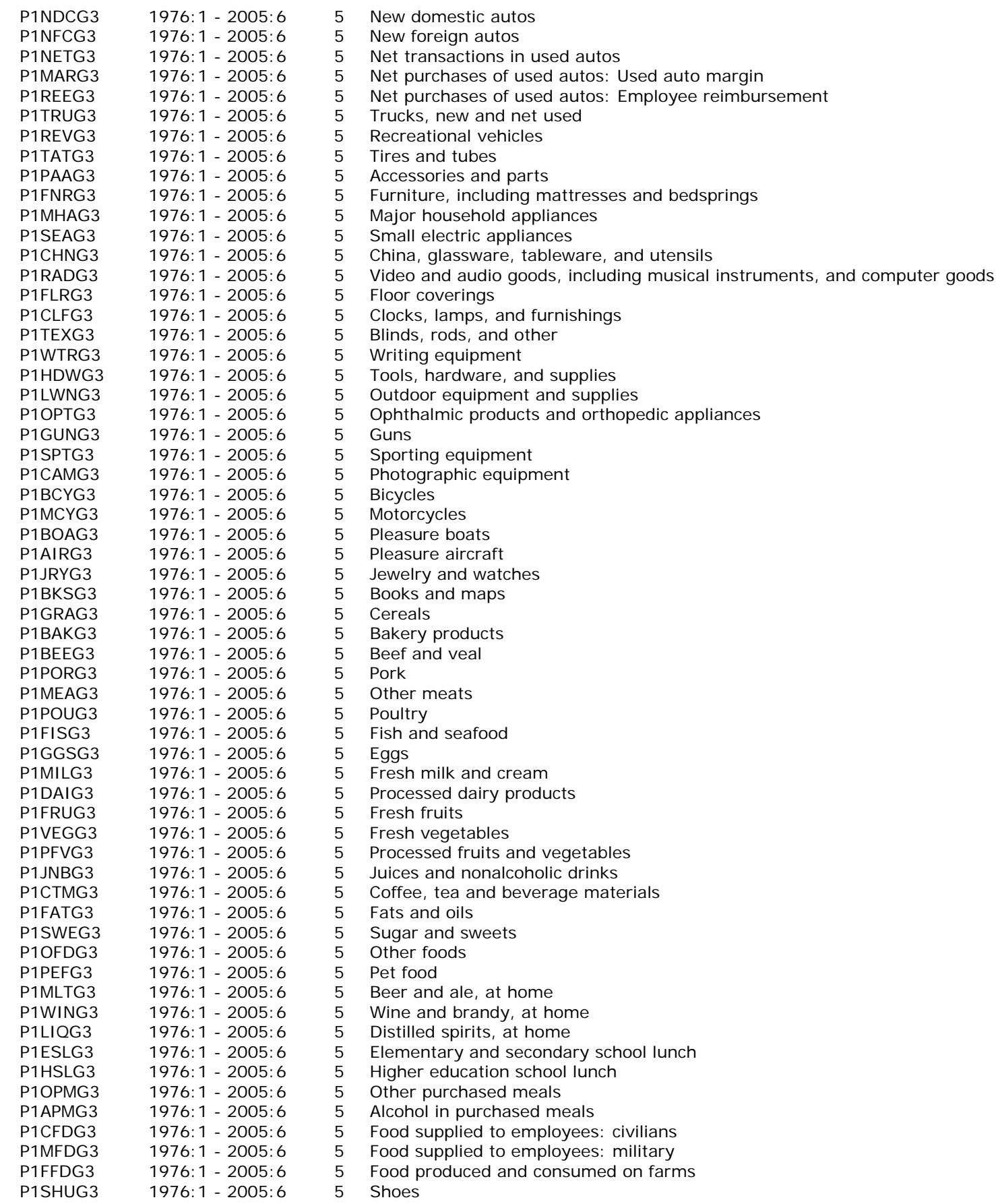




\begin{tabular}{|c|c|c|c|c|}
\hline 61 & P1WGCG3 & 1976: 1 - 2005: 6 & 5 & Clothing for females \\
\hline 62 & P1WICG3 & 1976: 1 - 2005: 6 & 5 & Clothing for infants \\
\hline 63 & P1WSGG3 & 1976: 1 - 2005: 6 & 5 & Sewing goods for females \\
\hline 64 & P1WUGG3 & 1976: 1 - 2005: 6 & 5 & Luggage for females \\
\hline 65 & P1MBCG3 & 1976: 1 - 2005: 6 & 5 & Clothing for males \\
\hline 66 & P1MSGG3 & 1976: 1 - 2005: 6 & 5 & Sewing goods for males \\
\hline 67 & P1MUGG3 & 1976: 1 - 2005: 6 & 5 & Luggage for males \\
\hline 68 & P1MICG3 & 1976: 1 - 2005: 6 & 5 & Standard clothing issued to military personnel (n.d.) \\
\hline 69 & P1GASG3 & 1976: 1 - 2005: 6 & 5 & Gasoline and other motor fuel \\
\hline 70 & P1LUBG3 & 1976: 1 - 2005: 6 & 5 & Lubricants \\
\hline 71 & P1OILG3 & 1976: 1 - 2005: 6 & 5 & Fuel oil \\
\hline 72 & P1LPGG3 & 1976: 1 - 2005: 6 & 5 & Liquefied petroleum gas and other fuel \\
\hline 73 & P1TOBG3 & 1976: 1 - 2005: 6 & 5 & Tobacco products \\
\hline 74 & P1SOAG3 & 1976: 1 - 2005: 6 & 5 & Soap \\
\hline 75 & P1CSMG3 & 1976: 1 - 2005: 6 & 5 & Cosmetics and perfumes \\
\hline 76 & P1OPHG3 & 1976: 1 - 2005: 6 & 5 & Other personal hygiene goods \\
\hline 77 & P1SDHG3 & 1976: 1 - 2005: 6 & 5 & Semidurable house furnishings \\
\hline 78 & P1CLEG3 & 1976: 1 - 2005: 6 & 5 & Cleaning preparations \\
\hline 79 & P1LIGG3 & 1976: 1 - 2005: 6 & 5 & Lighting supplies \\
\hline 80 & P1PAPG3 & 1976: 1 - 2005: 6 & 5 & Paper products \\
\hline 81 & P1RXDG3 & 1976: 1 - 2005: 6 & 5 & Prescription drugs \\
\hline 82 & P1NRXG3 & 1976: 1 - 2005: 6 & 5 & Nonprescription drugs \\
\hline 83 & P1MDSG3 & 1976: 1 - 2005: 6 & 5 & Medical supplies \\
\hline 84 & P1GYNG3 & 1976: 1 - 2005: 6 & 5 & Gynecological goods \\
\hline 85 & P1DOLG3 & 1976: $1-2005: 6$ & 5 & Toys, dolls, and games \\
\hline 86 & P1AMMG3 & 1976: 1 - 2005: 6 & 5 & Sport supplies, including ammunition \\
\hline 87 & P1FLMG3 & 1976: 1 - 2005: 6 & 5 & Film and photo supplies \\
\hline 88 & P1STSG3 & 1976: 1 - 2005: 6 & 5 & Stationery and school supplies \\
\hline 89 & P1GREG3 & 1976: 1 - 2005: 6 & 5 & Greeting cards \\
\hline 90 & P1ARTG3 & 1976: 1 - 2005: 6 & 5 & Expenditures abroad by U.S. residents: Government expenditures abroad \\
\hline 91 & PIARSG3 & 1976: $1-2005: 6$ & 5 & Expenditures abroad by U.S. residents: Other private services \\
\hline 92 & P1REMG3 & 1976: 1 - 2005: 6 & 5 & Less: Personal remittances in kind to nonresidents \\
\hline 93 & P1MGZG3 & 1976: 1 - 2005: 6 & 5 & Magazines and sheet music \\
\hline 94 & P1NWPG3 & 1976: 1 - 2005: 6 & 5 & Newspapers \\
\hline 95 & P1FLOG3 & 1976: 1 - 2005: 6 & 5 & Flowers, seeds, and potted plants \\
\hline 96 & P1OMHG3 & 1976: 1 - 2005: 6 & 5 & Owner occupied mobile homes \\
\hline 97 & P1OSTG3 & 1976: 1 - 2005: 6 & 5 & Owner occupied stationary homes \\
\hline 98 & P1TMHG3 & 1976: $1-2005: 6$ & 5 & Tenant occupied mobile homes \\
\hline 99 & P1TSPG3 & 1976: 1 - 2005: 6 & 5 & Tenant occupied stationary homes \\
\hline 100 & P1TLDG3 & 1976: 1 - 2005: 6 & 5 & Tenant landlord durables \\
\hline 101 & P1FARG3 & 1976: 1 - 2005: 6 & 5 & Rental value of farm dwellings \\
\hline 102 & P1HOTG3 & 1976: 1 - 2005: 6 & 5 & Hotels and motels \\
\hline 103 & P1HFRG3 & 1976: 1 - 2005: 6 & 5 & Clubs and fraternity housing \\
\hline 104 & P1HHEG3 & 1976: 1 - 2005: 6 & 5 & Higher education housing \\
\hline 105 & P1HESG3 & 1976: 1 - 2005: 6 & 5 & Elem and second education housing \\
\hline 106 & P1TGRG3 & 1976: 1 - 2005: 6 & 5 & Tenant group room and board \\
\hline 107 & P1TGLG3 & 1976: 1 - 2005: 6 & 5 & Tenant group employee lodging \\
\hline 108 & P1ELCG3 & 1976: 1 - 2005: 6 & 5 & Electricity \\
\hline 109 & P1NGSG3 & 1976: 1 - 2005: 6 & 5 & Gas \\
\hline 110 & P1WSMG3 & 1976: 1 - 2005: 6 & 5 & Water and sewerage maintenance \\
\hline 111 & P1REFG3 & 1976: $1-2005: 6$ & 5 & Refuse collection \\
\hline 112 & P1LOCG3 & 1976: 1 - 2005: 6 & 5 & Local and cellular telephone \\
\hline 113 & P1INCG3 & 1976: 1 - 2005: 6 & 5 & Intrastate toll calls \\
\hline 114 & P1ITCG3 & 1976: 1 - 2005: 6 & 5 & Interstate toll calls \\
\hline 115 & P1DMCG3 & 1976: 1 - 2005: 6 & 5 & Domestic service, cash \\
\hline 116 & P1DMIG3 & 1976: 1 - 2005: 6 & 5 & Domestic service, in kind \\
\hline 117 & P1MSEG3 & 1976: 1 - 2005: 6 & 5 & Moving and storage \\
\hline 118 & P1FIPG3 & 1976: 1 - 2005: 6 & 5 & Household insurance premiums \\
\hline 119 & P1FIBG3 & 1976: 1 - 2005: 6 & 5 & Less: Household insurance benefits paid \\
\hline 120 & P1RCLG3 & 1976: 1 - 2005: 6 & 5 & Rug and furniture cleaning \\
\hline 121 & P1EREG3 & 1976: $1-2005: 6$ & 5 & Electrical repair \\
\hline 122 & P1FREG3 & 1976: $1-2005: 6$ & 5 & Reupholstery and furniture repair \\
\hline 123 & P1PSTG3 & 1976: 1 - 2005: 6 & 5 & Postage \\
\hline 124 & P1MHOG3 & 1976: $1-2005: 6$ & 5 & Household operation services, n.e.c. \\
\hline 125 & P1ARPG3 & 1976: $1-2005: 6$ & 5 & Motor vehicle repair \\
\hline 126 & P1RLOG3 & 1976: 1 - 2005: 6 & 5 & Motor vehicle rental, leasing, and other \\
\hline 127 & P1TOLG3 & 1976: 1 - 2005: 6 & 5 & Bridge, tunnel, ferry, and road tolls \\
\hline 128 & P1AING3 & 1976: 1 - 2005: 6 & 5 & Insurance premiums for user-operated transportation \\
\hline 129 & P1IMTG3 & 1976: 1 - 2005: 6 & 5 & Local transportation: Mass transit systems \\
\hline 130 & P1TAXG3 & 1976: 1 - 2005: 6 & 5 & Taxicab \\
\hline 131 & P1IRRG3 & 1976: 1 - 2005: 6 & 5 & Railway \\
\hline 132 & P1IBUG3 & 1976: 1 - 2005: 6 & 5 & Bus \\
\hline 133 & P1IAIG3 & 1976: 1 - 2005: 6 & 5 & Airline \\
\hline 134 & P1TROG3 & 1976: 1 - 2005: 6 & 5 & Other \\
\hline 135 & P1PHYG3 & 1976: $1-2005: 6$ & 5 & Physicians \\
\hline 136 & P1DENG3 & 1976: $1-2005: 6$ & 5 & Dentists \\
\hline
\end{tabular}




\begin{tabular}{|c|c|c|c|c|}
\hline 137 & P1OPSG3 & $1976: 1-2005: 6$ & 5 & Other professional services \\
\hline 138 & P1NPHG3 & $1976: 1-2005: 6$ & 5 & Hospitals: Nonprofit \\
\hline 139 & P1FPHG3 & $1976: 1-2005: 6$ & 5 & Hospitals: Proprietary \\
\hline 140 & P1GVHG3 & $1976: 1-2005: 6$ & 5 & Hospitals: Government \\
\hline 141 & P1NRSG3 & $1976: 1-2005: 6$ & 5 & Nursing homes \\
\hline 142 & P1MING3 & $1976: 1-2005: 6$ & 5 & Health insurance: Medical care and hospitalization \\
\hline 143 & P1IING3 & 1976: $1-2005: 6$ & 5 & Health insurance: Income loss \\
\hline 144 & P1PWCG3 & $1976: 1-2005: 6$ & 5 & Health insurance: Workers' compensation \\
\hline 145 & P1MOVG3 & $1976: 1-2005: 6$ & 5 & Admissions to motion picture theaters \\
\hline 146 & P1LEGG3 & $1976: 1-2005: 6$ & 5 & Admissions to theaters and opera, and entertainments of nonprofit instit. (except athletics) \\
\hline 147 & P1SPEG3 & $1976: 1-2005: 6$ & 5 & Admissions to spectator sports \\
\hline 148 & P1RTVG3 & $1976: 1-2005: 6$ & 5 & Radio and television repair \\
\hline 149 & P1CLUG3 & $1976: 1-2005: 6$ & 5 & Clubs and fraternal organizations \\
\hline 150 & P1SIGG3 & $1976: 1-2005: 6$ & 5 & Sightseeing \\
\hline 151 & P1FLYG3 & $1976: 1-2005: 6$ & 5 & Private flying \\
\hline 152 & P1BILG3 & $1976: 1-2005: 6$ & 5 & Bowling and billiards \\
\hline 153 & P1CASG3 & $1976: 1-2005: 6$ & 5 & Casino gambling \\
\hline 154 & P1OPAG3 & $1976: 1-2005: 6$ & 5 & Other commercial participant amusements \\
\hline 155 & P1PARG3 & $1976: 1-2005: 6$ & 5 & Pari-mutuel net receipts \\
\hline 156 & P1REOG3 & 1976: $1-2005: 6$ & 5 & Other recreation \\
\hline 157 & P1SCLG3 & $1976: 1-2005: 6$ & 5 & Shoe repair \\
\hline 158 & P1DRYG3 & $1976: 1-2005: 6$ & 5 & Drycleaning \\
\hline 159 & P1LGRG3 & $1976: 1-2005: 6$ & 5 & Laundry and garment repair \\
\hline 160 & P1BEAG3 & $1976: 1-2005: 6$ & 5 & Beauty shops, including combination \\
\hline 161 & P1BARG3 & $1976: 1-2005: 6$ & 5 & Barber shops \\
\hline 162 & P1WCRG3 & $1976: 1-2005: 6$ & 5 & Watch, clock, and jewelry repair \\
\hline 163 & P1CRPG3 & $1976: 1-2005: 6$ & 5 & Miscellaneous personal services \\
\hline 164 & P1BROG3 & $1976: 1-2005: 6$ & 5 & Brokerage charges and investment counseling \\
\hline 165 & P1BNKG3 & $1976: 1-2005: 6$ & 5 & Bank service charges, trust services, and safe deposit box rental \\
\hline 166 & P1IMCG3 & $1976: 1-2005: 6$ & 5 & Commercial banks \\
\hline 167 & P1IMNG3 & $1976: 1-2005: 6$ & 5 & Other financial institutions \\
\hline 168 & P1LIFG3 & $1976: 1-2005: 6$ & 5 & Expense of handling life insurance and pension plans \\
\hline 169 & P1GALG3 & $1976: 1-2005: 6$ & 5 & Legal services \\
\hline 170 & P1FUNG3 & $1976: 1-2005: 6$ & 5 & Funeral and burial expenses \\
\hline 171 & P1UNSG3 & $1976: 1-2005: 6$ & 5 & Labor union expenses \\
\hline 172 & P1ASSG3 & $1976: 1-2005: 6$ & 5 & Profession association expenses \\
\hline 173 & P1GENG3 & $1976: 1-2005: 6$ & 5 & Employment agency fees \\
\hline 174 & P1AMOG3 & $1976: 1-2005: 6$ & 5 & Money orders \\
\hline 175 & P1CLAG3 & $1976: 1-2005: 6$ & 5 & Classified ads \\
\hline 176 & P1ACCG3 & $1976: 1-2005: 6$ & 5 & Tax return preparation services \\
\hline 177 & P1THEG3 & $1976: 1-2005: 6$ & 5 & Personal business services, n.e.c. \\
\hline 178 & P1PEDG3 & $1976: 1-2005: 6$ & 5 & Private higher education \\
\hline 179 & P1GEDG3 & $1976: 1-2005: 6$ & 5 & Public higher education \\
\hline 180 & P1ESCG3 & $1976: 1-2005: 6$ & 5 & Elementary and secondary schools \\
\hline 181 & P1NSCG3 & $1976: 1-2005: 6$ & 5 & Nursery schools \\
\hline 182 & P1VEDG3 & $1976: 1-2005: 6$ & 5 & Commercial and vocational schools \\
\hline 183 & P1REDG3 & $1976: 1-2005: 6$ & 5 & Foundations and nonprofit research \\
\hline 184 & P1POLG3 & $1976: 1-2005: 6$ & 5 & Political organizations \\
\hline 185 & P1MUSG3 & $1976: 1-2005: 6$ & 5 & Museums and libraries \\
\hline 186 & P1FOUG3 & $1976: 1-2005: 6$ & 5 & Foundations to religion and welfare \\
\hline 187 & P1WELG3 & $1976: 1-2005: 6$ & 5 & Social welfare \\
\hline 188 & P1RELG3 & $1976: 1-2005: 6$ & 5 & Religion \\
\hline 189 & P1FTRG3 & $1976: 1-2005: 6$ & 5 & Foreign travel by U.S. residents (110) \\
\hline 190 & P1EXFG3 & $1976: 1-2005: 6$ & 5 & Less: Expenditures in the United States by nonresidents (112) \\
\hline 191 & P1TDGG3 & $1976: 1-2005: 6$ & 5 & Durable goods \\
\hline 192 & P1TNDG3 & $1976: 1-2005: 6$ & 5 & Nondurable goods \\
\hline 193 & P1TSSG3 & $1976: 1-2005: 6$ & 5 & Services \\
\hline 194 & PPCE & $1976: 1-2005: 6$ & 5 & Personal Consumption Expenditures (all items) \\
\hline
\end{tabular}




\section{APPENDIX C - Producer Price Indices}

Format is as in Stock and Watson (2002) paper: series number; series mnemonic (NAICS code); data span; transformation code and series description as appears in the database. The transformation for all data was first difference of logarithms, which is coded as 5 . This data set contains 154 monthly series with no missing observations. All series are downloaded from the website of BLS.

\begin{tabular}{|c|c|}
\hline 311119 & 1976: 1 - 2005: \\
\hline $311119 p$ & 1976: 1 - 2005: \\
\hline 311211 & 1976: 1 - 2005: \\
\hline 311212 & 1976: $1-2005$ \\
\hline 311213 & $1976: 1-2005$ \\
\hline $311223 a$ & 1976: 1 - 2005 \\
\hline $311225 p$ & 1976: 1 - 2005 \\
\hline 311311 & 1976: $1-2005$ \\
\hline 311313 & 1976: $1-2005$ \\
\hline 311412 & $1976: 1-2005$ \\
\hline 311520 & 1976: $1-2005$ \\
\hline 311920 & 1976: $1-2005$ \\
\hline 312140 & 1976: 1 - 2005 \\
\hline $32211-$ & 1976: $1-2005$ \\
\hline $32213-$ & $1976: 1-2005$ \\
\hline $325620 p$ & $1976: 1-2005$ \\
\hline 325920 & 1976: 1 - 2005 \\
\hline 32731- & 1976: $1-2005$ \\
\hline 327320 & 1976: 1 - 2005 \\
\hline 327410 & $1976: 1-2005$ \\
\hline 327420 & 1976: $1-2005$ \\
\hline 327910 & 1976: $1-2005$ \\
\hline 331210 & 1976: $1-2005$ \\
\hline 333210 & 1976: 1 - 2005 \\
\hline 334310 & 1976: $1-2005$ \\
\hline 335110 & 1976: 1 - 2005 \\
\hline 336370 & 1976: $1-2005$ \\
\hline 337910 & 1976: 1 - 2005 \\
\hline 311421 & 1976: 1 - 2005 \\
\hline 311423 & 1976: 1 - 2005 \\
\hline 311513 & $1976: 1-2005$ \\
\hline 311611 & 1976: 1 - 2005 \\
\hline 311612 & 1976: 1 - 2005 \\
\hline 311613 & 1976: $1-2005$ \\
\hline 311711 & 1976: $1-2005$ \\
\hline 311712 & 1976: $1-2005$ \\
\hline $311813 p$ & 1976: $1-2005$ \\
\hline 3118233 & 1976: $1-2005$ \\
\hline $312111 p$ & 1976: 1 - 2005 \\
\hline 312221 & 1976: $1-2005$ \\
\hline 3122291 & 1976: 1 - 2005 \\
\hline 313111 & 1976: 1 - 2005 \\
\hline 3133111 & 1976: 1 - \\
\hline 315111 & 1976: 1 - 2005 \\
\hline 315191 & 1976: 1 - 2005 \\
\hline 315223 & 1976: $1-2005$ \\
\hline 315224 & 1976: 1 - 2005 \\
\hline 315993 & 1976: $1-2005$ \\
\hline 316211 & 1976: 1 - 2005 \\
\hline 316213 & 1976: 1 - 2005 \\
\hline 316214 & 1976: 1 - 2005 \\
\hline 316992 & 1976: $1-2005$ \\
\hline 321212 & 1976: 1 - 2005 \\
\hline 3212191 & 1976: 1 - 2005 \\
\hline 3219181 & 1976: 1 - 2005 \\
\hline 321991 & 1976: 1 - 2005 \\
\hline 3221211 & 1976: 1 - 2005 \\
\hline 322214 & 1976: $1-2005$ \\
\hline 324121 & $1976: 1-2005$ \\
\hline 324122 & 1976: 1 - \\
\hline $324191 p$ & 1976: 1 - \\
\hline 325181 & 1976: 1 - \\
\hline 3251881 & 1976: 1 - \\
\hline
\end{tabular}

5 Other animal food manufacturing

Other animal food manufacturing (primary products)

Flour Milling

Rice milling

Malt $\mathrm{mfg}$

Other oilseed processing (cottonseed cake and meal and other byproducts)

Fats and oils refining and blending (primary products)

Sugarcane mills

Beet sugar manufacturing

Frozen specialty food manufacturing

Ice cream and frozen dessert mfg

Coffee and tea manufacturing

Distilleries

Pulp mills

Paperboard mills

Toilet preparation mfg (primary products)

Explosives manufacturing

Cement $\mathrm{mfg}$

Ready mixed concrete mfg and dist

Lime

Gypsum building products manufacturing

Abrasive product manufacturing

I ron steel pipe \& tube mfg from purch steel

Sawmill \& woodworking machinery $\mathrm{mfg}$

Audio \& video equipment mfg

Electric lamp bulb \& part mfg

Motor vehicle metal stamping

Mattress mfg

Fruit and vegetable canning

Dried and dehydrated food manufacturing

Cheese manufacturing

Animal except poultry slaughtering

Meat processed from carcasses

Rendering and meat byproduct processing

Seafood canning

Fresh \& frozen seafood processing

Frozen cakes pies $\&$ other pastries mfg (Primary products)

Dry pasta manufacturing (macaroni spaghetti vermicelli and noodles)

Soft drinks manufacturing (primary products)

Cigarettes

Other tobacco product mfg (cigars)

Yarn spinning mills

Broadwoven fabric finishing mills

(finished cotton broadwoven fabrics not finished in weaving mills)

Sheer hosiery mills

Outerwear knitting mills

Men's boy's cut $\&$ sew shirt excl work mfg

Men's boy's cut $\&$ sew trouser slack jean mfg

Men's and boys' neckwear mfg

Rubber and plastic footwear manufacturing

Men's footwear excl athletic mfg

Women's footwear excl athletic mfg

Women's handbag \& purse mfg

Softwood veneer or plywood $\mathrm{mfg}$

Reconstituted wood product mfg (particleboard produced at this location) Other millwork including flooring

(wood moldings except prefinished moldings made from purchased moldings)

Manufactured homes mobile homes mfg

Paper except newsprint mills (clay coated printing and converting paper)

Fiber can tube drum \& other products $\mathrm{mfg}$

Asphalt paving mixture \& block mfg

Asphalt shingle \& coating materials $\mathrm{mfg}$

Petroleum lubricating oils and greases (primary products)

Alkalies and chlorine

All other basic inorganic chemical manufacturing (sulfuric acid gross new and fortified) 


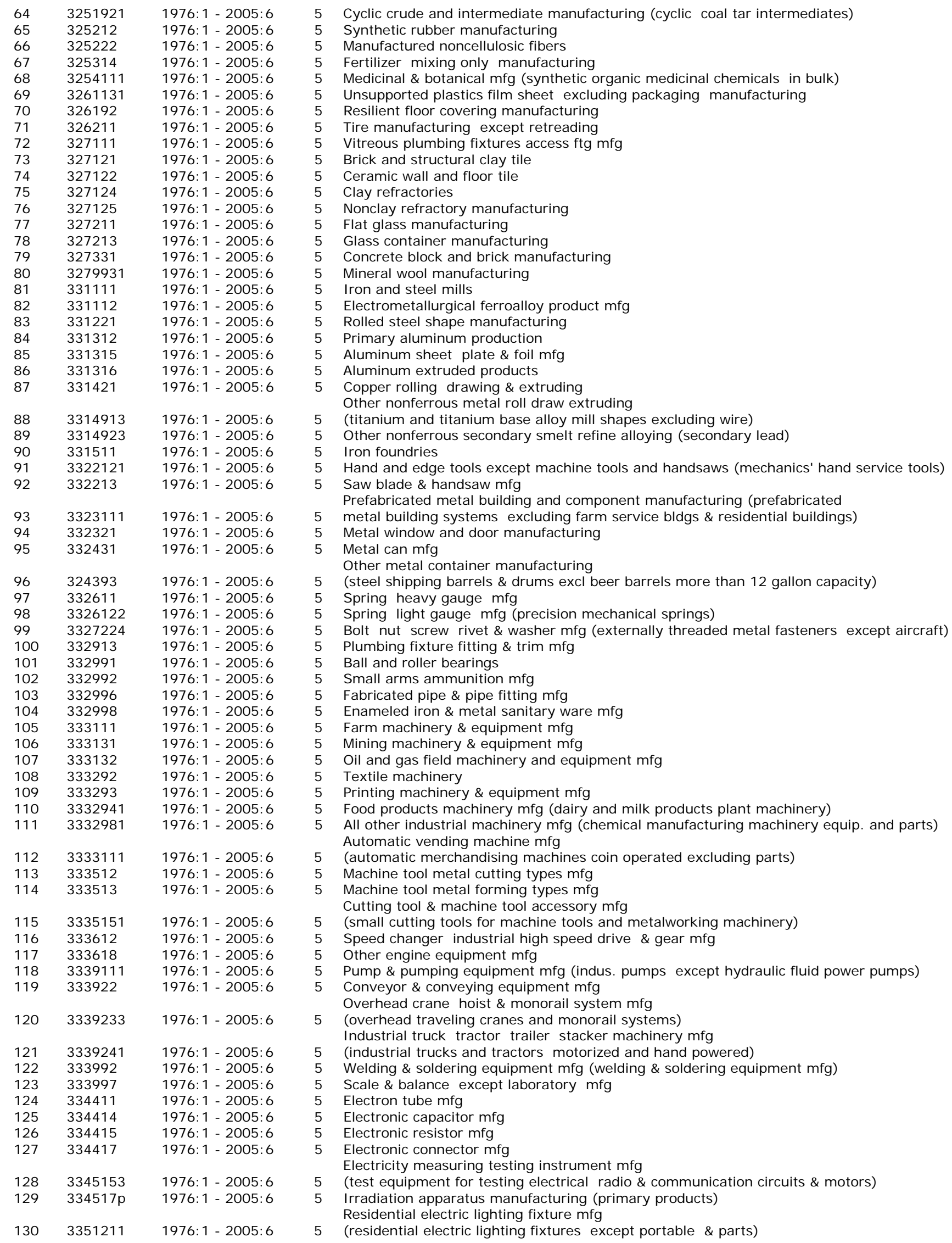




\begin{tabular}{|c|c|c|c|c|}
\hline 131 & 335122 & 1976: $1-2005: 6$ & 5 & Commercial electric lighting fixture $\mathrm{mfg}$ \\
\hline 132 & 335129 & 1976: 1 - 2005: 6 & 5 & Other lighting equipment $\mathrm{mfg}$ \\
\hline 133 & 335212 & 1976: $1-2005: 6$ & 5 & Household vacuum cleaner mfg \\
\hline 134 & 335221 & 1976: 1 - 2005: 6 & 5 & Household cooking appliance mfg \\
\hline 135 & 335311 & 1976: $1-2005: 6$ & 5 & Power distribution specialty transformer mfg \\
\hline 136 & 335312 & 1976: 1 - 2005: 6 & 5 & Motor \& generator $\mathrm{mfg}$ \\
\hline 137 & $335314 p$ & $1976: 1-2005: 6$ & 5 & Relay \& industrial control mfg (primary products) \\
\hline 138 & 335911 & 1976: 1 - 2005: 6 & 5 & $\begin{array}{l}\text { Storage battery } \mathrm{mfg} \\
\text { Other communication and energy wire } \mathrm{mfg}\end{array}$ \\
\hline 139 & 3359291 & 1976: 1 - 2005: 6 & 5 & (power wire and cable made in plants that draw wire) \\
\hline 140 & 335932 & $1976: 1-2005: 6$ & 5 & Noncurrent carrying wiring device mfg \\
\hline 141 & $335991 p$ & 1976: $1-2005: 6$ & 5 & Carbon \& graphite product mfg (primary products) \\
\hline 142 & $336321 p$ & 1976: $1-2005: 6$ & 5 & Vehicular lighting equipment mfg (primary products) \\
\hline 143 & 337121 & $1976: 1-2005: 6$ & 5 & Upholstered household furniture mfg \\
\hline 144 & 337122 & 1976: 1 - 2005: 6 & 5 & Wood household furniture except upholstered \\
\hline 145 & 337124 & 1976: $1-2005: 6$ & 5 & Metal household furniture \\
\hline 146 & 337211 & 1976: 1 - 2005: 6 & 5 & Wood office furniture $\mathrm{mfg}$ \\
\hline 147 & 3372141 & 1976: $1-2005: 6$ & 5 & $\begin{array}{l}\text { Nonwood office furniture (office seating including upholstered nonwood) } \\
\text { Jewelry except costume } \mathrm{mfg}\end{array}$ \\
\hline 148 & 3399111 & 1976: 1 - 2005: 6 & 5 & (jewelry made of solid platinum metals and solid karat gold) \\
\hline 149 & 3399123 & 1976: 1 - 2005: 6 & 5 & Silverware \& hollowware mfg ( Flatware and carving sets made wholly of metal) \\
\hline 150 & 339931 & 1976: 1 - 2005: 6 & 5 & Doll \& stuffed toy mfg \\
\hline 151 & 339932 & 1976: 1 - 2005: 6 & 5 & Game toy \& children's vehicle mfg \\
\hline 152 & 339944 & 1976: 1 - 2005: 6 & 5 & $\begin{array}{l}\text { Carbon paper } \& \text { inked ribbon } \mathrm{mfg} \\
\text { Fastener button needle } \& \text { pin } \mathrm{mfg}\end{array}$ \\
\hline 153 & 3399931 & 1976: 1 - 2005: 6 & 5 & (Buttons and parts except for precious or semiprecious metals and stones) \\
\hline 154 & 3399945 & 1976: $1-2005: 6$ & 5 & Broom brush \& mop mfg (other brushes) \\
\hline
\end{tabular}

\section{APPENDIX D - Cross-Sectional I ndustry Characteristics}

For the cross-sectional regressions we use the following data sources:

C4 - Concentration ratio. Represents the percentage of sales made by the largest 4 firms in the industry. Source. Bureau of the Census 1997.

Profit rates - average gross profit rates for 1997-2001 based on tax accounting. Source: 2001 Annual Survey of Manufacturers. 